UCRL-ID-135318

\title{
Lessons Learned from the First \\ U.S./Russian Federation Joint Tabletop \\ Exercise to Prepare for Conducting On- \\ Site Inspections Under the \\ Comprehensive Nuclear Test Ban Treaty
}

C. Filarowski, S. Kreek, A. Smith, J. Sweeney, J. Wild, R. Gough, P. Rockett, G. Macleod, J.R. Russell, W. Hawkins, K. Wohletz, S. Knowles

\section{March 24, 1999}

U.S. Department of Energy

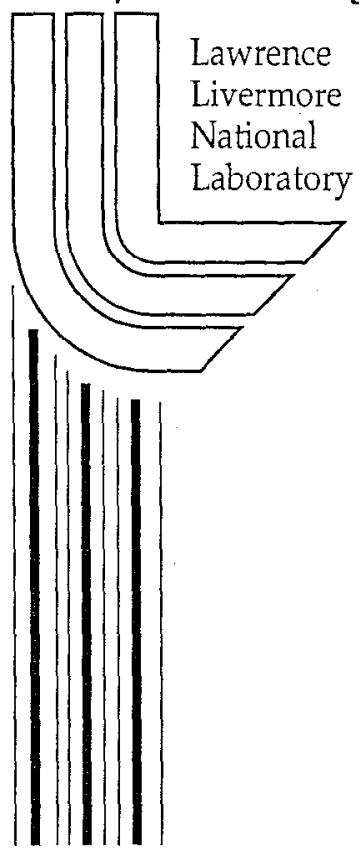




\section{DISCLAIMER}

This document was prepared as an account of work sponsored by an agency of the United States Government. Neither the United States Government nor the University of California nor any of their employees, makes any warranty, express or implied, or assumes any legal liability or responsibility for the accuracy, completeness, or usefulness of any information, apparatus, product, or process

disclosed, or represents that its use would not infringe privately owned rights. Reference herein to any specific commercial product, process, or service by trade name, trademark, manufacturer, or otherwise, does not necessarily constitute or imply its endorsement, recommendation, or favoring by the United States Government or the University of California. The views and opinions of authors expressed herein do not necessarily state or reflect those of the United States Government or the University of California, and shall not be used for advertising or product endorsement purposes. 


\section{Contents}

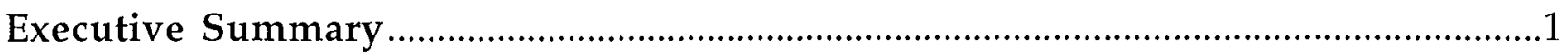

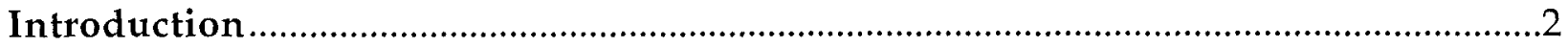

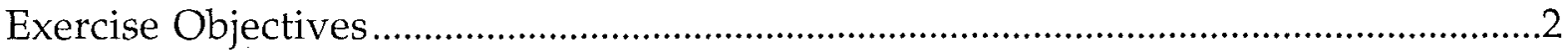

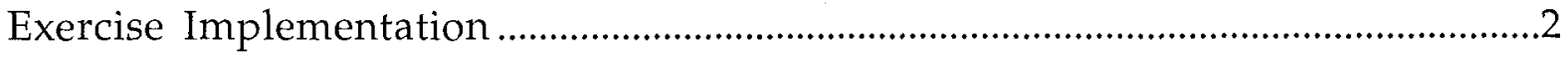

Scenario Descriptions and Summary of Proceedings .........................................................4

Russian-Developed Scenario .................................................................................

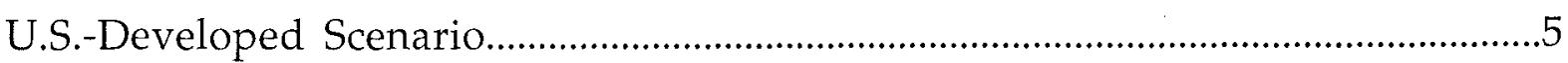

OSI Technical and Operational Lessons Learned................................................................6

Overflight Activities ....................................................................................................

Ground-Based Visual Observations ...........................................................................

Passive Seismological Monitoring.....................................................................10

Radionuclide Detection and Analysis....................................................................12

Logistics and Other OSI Operation Issues................................................................14

OSI Overall Strategy Lessons Learned..........................................................................15

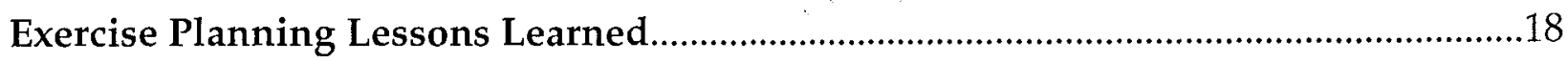

Exercise Development and Execution....................................................................18

Data Preparation and Presentation ...............................................................................20

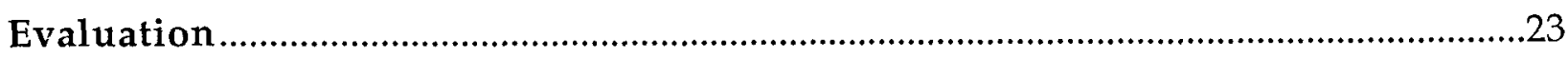

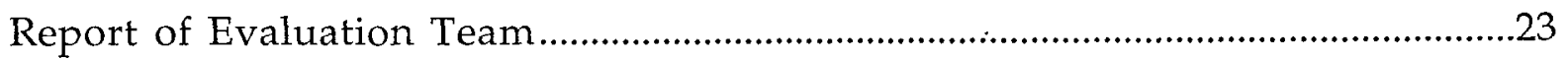

Proposed Next Steps for U.S./RF Interactions on CTBT OSI ..........................................26

Appendix I: $\quad$ RF Scenario Consultation and Clarification Package

Appendix II: $\quad$ U.S. Scenario Consultation and Clarification Package

Appendix III: Exercise Planning, Coordination, Development and Implementation Team 
Lessons Learned from the First U.S./Russian Federation Joint Tabletop Exercise to Prepare for Conducting On-Site Inspections Under the Comprehensive Nuclear Test Ban Treaty

Note: Pages with "CTBTO Restricted" statement are samples only. 


\section{Executive Summary}

A U.S./Russian Federation Joint Tabletop Exercise took place in Snezhinsk, Russia, from 19 to 24 October 1998 whose objectives were to examine the functioning of an Inspection Team (IT) in a given scenario, to evaluate the strategies and techniques employed by the IT, to identify ambiguous interpretations of treaty provisions that needed clarification, and to confirm the overall utility of tabletop exercises to assist in developing an effective Comprehensive Test Ban Treaty (CTBT) verification regime.

To achieve these objectives, the United States and Russian Federation (RF) agreed that two exercises would be conducted. The first would be developed by the RF, who would act as controller and as the inspected State Party (ISP), while the United States would play the role of the IT. The roles would be reversed in the second exercise; the United States would develop the scenario and play the ISP, while the RF would play the IT. A joint control team, comprised of members of both the U.S. and RF control teams, agreed on a number of ground rules for the two exercises and established a joint Fvaluation Team to evaluate both of the exercises against the stated objectives.

To meet time limitations, the scope of this joint exercise needed to be limited. The joint control team decided that each of the two exercises would not go beyond the first 25 days of an on-site inspection (OSI) and that the focus would be on examining the decision-making of the IT as it utilizcd the various technologies to clarify whether a nuclear test explosion had taken place. Hence, issues such as logistics, restricted access, and activities prior to Point of Entry (POE) would be played only to the extent needed to provide for a realistic context for the exercises' focus on inspection procedures, sensor deployments, and data interpretation.

Each of the exercises began at the POE and proceeded with several iterations of negotiations between the IT and ISP, instrument deployments, and data evaluation by the IT. By the end of each of the exercises, each IT had located the site of the underground nuclear explosion (UNE). While this validated the methods employed by each of the ITs, the Evaluation Team noted that each IT employed different search strategies and that each strategy had both advantages and disadvantages. The exercises also highlighted ambiguities in interpretation of certain treaty provisions related to overflights and seismic monitoring. Likewise, a substantial number of lessons were learned relating to radionuclide monitoring and the impact of logistical constraints on successful OSI execution. These lessons are discussed more fully in the body of this report.

Notwithstanding the overall positive assessment by the U.S. and RF participants, as well as by the Evaluation Team, that the exercise had met its objectives, there were a variety of areas identified that could be improved in subsequent OSI exercises. Some of these included reexamination of the methods used to convey visual observation data in an exercise; the amount of time compression employed; and the need for better verification of agreements pertaining to the structure, format, and other rules of the exercise.

This report summarizes the lessons learned pertaining to both the technical and operational aspects of an OSI as well as to those pertaining to the planning and execution of an OSI exercise. It concludes with comments from the Evaluation Team and proposed next steps for future U.S./RF interactions on CTBT OSIs. 


\section{Introduction}

\section{Exercise Objectives}

A U.S./Russian Federation Joint Tabletop Exercise took place in Snezhinsk, Russia, from 19 to 24 October 1998, whose objectives were the following:

- To simulate the actions of the Inspection Team (IT), including interactions with the inspected State Party (ISP), in order to examine different ways the United States and Russian Federation (RF) approach inspections and develop appropriate recommendations for the international community.

- To identify ambiguities and contradictions in the interpretation of Treaty and Protocol provisions that might become apparent in the course of an inspection and that need clarification in connection with the development of Operational Manuals and on-site inspection (OSI) infrastructure.

- To confirm the efficacy of using bilateral tabletop exercises to assist in developing an effective Comprehensive Test Ban Treaty (CTBT) verification regime.

- To identify strong and weak points in the preparation and implementation methods of such exercises for the purpose of further improving possible future exercises.

\section{Exercise Implementation}

To achieve these objectives, the United States and the RF agreed that rather than conducting onc excrcise with mixed teams, which would require a great deal of time to organize and plan, two exercises would be conducted. The first would be developed by the RF, who would act as controller and the ISP, while the United States would play the role of the IT. The roles would be reversed in the second exercise; the United States would develop the scenario and play the ISP, while the RF would play the IT.

A joint control team, comprised of members of both the U.S. and RF control teams, agreed on a number of ground rules for the two exercises and established a joint Evaluation Team to evaluate both of the exercises against the stated objectives. This latter group was comprised of two people from the United States and two from the Russian Federation. Their task was to observe the functioning of all of the teams and their interactions and to lead the post-exercise discussion, commenting on the preparation and presentation of the data, the strategies employed by the teams in their roles as IT and ISP, and the utility of the exercise as a whole. The comments from the Evaluation Team can be found in a subsequent portion of this report.

As in the U.S.-only tabletop exercise, the scope of this joint exercise needed to be limited. To effectively examine the issues stated in the objectives, the joint control team decided that each of the two exercises would not go beyond the first 25 days of an OSI and that the focus should examine the decision-making of the IT as it utilized the various technologies to clarify whether a nuclear explosion had taken place-i.e., where, how, and when the IT deployed its permitted sensors and conducted 
overflight and ground-based visual observation; how the IT evaluated the data received from those inspection activities; and how it then redeployed its inspection sensors and visual observation assets. Hence, issues such as logistics, restricted access, and activities prior to Point of Entry (POE) would be played only to the extent needed to provide for a realistic scenario and interaction among the teams. 


\section{Russian-Developed Scenario}

State $X$, a party to the CTBT, requests clarification of a magnitude 4.0 event detected by the International Data Center (IDC) on 3 October 1998 occurring in State Y. State X claims that the ratio of magnitudes of surface-to-body waves indicates a high probability that this event is of an explosive nature and, since the International Monitoring System (IMS) has never previously detected explosive activity at this level in this region of State $Y$, State $X$ is concerned about possible CTBT noncompliance.

State $Y$ responds that there was, indeed, an explosion on the date specified by State $X$, but that this was a chemical explosion carried out at an open-cast mine to test new cost-effective methods of crushing rock. Further, State $Y$ claims that previous conventional explosions in this same quarry were detected by the IMS as magnitude 2.5 and 3.0 events, but these did not cause CTBT compliance concerns. Additionally, State $Y$ states that no IMS radionuclide stations detected any evidence of noncompliance.

State $X$ is not satisfied by this explanation, claiming that the data provided by State $Y$ are inconsistent with those of a chemical explosion and elaborating on State Y's recent intensified efforts to develop their nuclear program. For these reasons, State $X$ requests an on-site inspection of State $Y$. A copy of this Consultation and Clarification Package can be found in Appendix I.

The play of this scenario, in which the United States acted as the IT, and the RF acted as the ISP, began with the POE briefing, which provided general information about the inspection area, the base camp, the aircraft available for the overflight, and other logistical support information. The U.S. IT began its inspection with an overflight of selected portions of the inspection area while setting up a base camp. The IT also planned routes for ground-based visual inspections and deployed several seismic- and radionuclide-monitoring sensors, also in a targeted search of selected portions of the inspection area.

The U.S. IT initially concentrated on investigating the mines and the radiological waste storage site and interviewing the mine and waste site managers. Results of the visual observations at these areas were generally uninteresting, except for the radiological waste storage site, where radionuclide monitoring produced a "hit" for Cesium.

Initial seismic data results indicated 84 "event" detections on days three and four. Of these, only one event involved a multiple (2) station detection. When it became obvious that the Russians were including a lot of local noise in the data (such as heavy equipment or machinery operation, which would be detected only by a single station), the U.S. IT began to look solely for multiple-station detections to get "reliable" events. Eventually, the IT detected quite a few events consistently occurring near one particular portion of the inspection area and concentrated seismic stations there. Eventually, from a plot of all the multiple-station events detected, the U.S. IT was able to pinpoint a hypocenter for the suspect event. Gas sampling was also done in this area and produced an ${ }^{37} \mathrm{Ar}$ "hit" on day 15. 


\section{U.S.-Developed Scenario}

Atlantia, a party to the CTBT, requests clarification from Pacifica regarding an IMS-detected cvent on 1 November 1998. The event, a 3.6 magnitude scismic event was detected at a depth of less than $5 \mathrm{~km}$, and it occurred in an area of increased ambiguous activity, which included tunneling.

Pacifica responded that it was investigating the source of this event but believed it to have been caused by an unintentionally large chemical explosion at a commercial surface coal mine located in the vicinity of the reported event. Pacifica further stated that personnel at the mine had planned a ripple-fire explosion in the course of routine mining activity, but for unknown reasons, inadvertently detonated all explosives simultaneously. News reports of a 4.1 earthquake in the vicinity of the reported event were also furnished by Pacifica to provide another possible explanation for the IDCreported event. Pacifica also drew attention to the fact that no other component of the IMS detected any evidence of noncompliance, including two radionuclide stations and one infrasound station, all within $500 \mathrm{~km}$ of the event.

Atlantia was unsatisfied with this explanation, claiming that it is highly unusual that a chemical explosion in a surface mine could have caused a magnitude 3.6 event. Such an explosion would require a quantity of explosives far in excess of any known mining practices for the type of procedure claimed by Pacifica. Also, Atlantia claimed that if this event had been caused by such a large chemical explosion, the infrasound station in the area would have detected it. For these reasons, Atlantia requested an on-site inspection of Pacifica to clarify whether a nuclear explosion had been carried out. A copy of this Consultation and Clarification Package can be found in Appendix II.

When the IT arrived at the POE, they were briefed about the inspection area, the base camp, and the logistical support that they would be provided by the ISP. In their initial deployment, the Russian IT deployed 30 seismic stations on days two and three of the inspection, in a fixed 4-km grid, concentrating on the large central alluvial valley in the inspection area. The reason for this is that the aftershock rate decays most quickly in alluvium. The RF IT immediately detected aftershocks from the underground nuclear test, but had difficulty interpreting the results because the coarse station coverage led to large errors in locations and poor determinations of depth. The RF IT continued monitoring up to 21 days, when they detected the presence of ${ }^{37} \mathrm{Ar}$. 


\section{OSI Technical and Operational Lessons Learned}

Each of the following sections provides a summary of the lessons that were learned as a result of the U.S./RF Joint Tabletop Exercise, as they relate to technical and operational OSI issues. Overflight activities are presented first, followed by ground-based visual observations, passive seismological monitoring, radionuclide monitoring, and logistics issues. The last section, OSI overall strategy lessons learned, describes the strategies employed by the U.S. and Russian teams as they simulated inspectors and members of the ISP. 


\section{Overflight Activities}

The U.S./RF Joint Tabletop exercises raised a variety of issues regarding the intent, utility, and proper conduct of an overflight. These issues, discussed below, specifically pertain to flight platforms, flight speed, extent of initial search, use of real-time dosimeters in flight, effects of varying terrain, and duration of flights. While the opinions of the observers and evaluators regarding the utility of the overflight varied greatly, it was clear that in both the Russian and the U.S. scenarios, the overflight fulfilled its primary mission-to narrow the inspection area.

Flight platform. This set of exercises demonstrated the benefit of using a helicopter rather than fixed-wing aircraft for CTBT on-site inspections. Even in a full-grid search, as employed by the Russian IT, the helicopter had sufficient speed to examine the entire $1000 \mathrm{~km}^{2}$ area and still allow for follow-on overflights, consistent with the 12-hour limit. Additionally, the helicopter could hover, permitting close-in examination of areas either before the ground team arrived at a location or supplementing the ground inspection when an area was not easily accessible by ground transportation.

Duration of flights. A Russian Evaluation Team member remarked that no nation would permit the frequent use of brief overflights for many days or weeks, as the U.S. IT attempted to exercise. The intention of the treaty writers, as reported by the Evaluation Team members, was to complete the overflight early in the inspection. Thus, while an IT might segment the allotted 12 hours into several trips, the IT should not depend upon access to the aircraft beyond the first two to three days, unless weather conditions interfere with the possibility of an early overflight.

Extent of initial search. Differences between U.S. and RF overflight strategies were most clearly defined in the use of broad area searches by the Russians as compared to the focused searches initiated by the U.S. team. The Russian overflights were full-grid searches that assumed the maps received were not complete and that all cultural features were not displayed. The U.S, team instead focused upon unclear symbols on the map to get a closer look at preidentified cultural features, trusting that they had fairly complete maps. While each approach has its merits, satellite images will most likely be available to a real IT that would show extensive road patterns and the larger facilities, possibly avoiding the need for such broad area searches in the overflight.

Use of real-time dosimeters in flight. If use of a wide spectrum gamma counter were permitted in the overflight, this could make a broad search quite useful in identifying radioactive sources over the inspection area. It was clear that both sides in this exercise wished to use some sort of Geiger counter or low-resolution sodium iodide $\mathrm{NaI}(\mathrm{Tl})$ detector in the initial overflight. Even pocket-size ratemeters (or chirpers) were considered for this purpose.

Effect of varying terrain. The terrain, vegetation, and time of year of an OSI will have a substantial impact upon the information that may be gathered during visual observations, both from the air and on the ground. The Siberian wetlands are muddy and difficult to maneuver in, and the thick pine and birch forests obscure many small roads on the ground, unless one is directly above them. 
Equipment and personnel on overflight. Of the permitted equipment, the still cameras and Global Positioning System locators appear to be the most important. Simulating the use of binocular views in the exercise was difficult, but binoculars would also prove quite valuable during an overflight (perhaps more so from a fixed-wing aircraft than from a vibrating helicopter). Use of video equipment raised a problem generated from having the ISP provide the photographer(s). If only one photographer was provided, then the IT could not record from two cameras at once, or from a still camera and a video camera. The IT will clearly need to negotiate this issue with the ISP. Whether there are two ISP photographers or one ISP and one IT photographer, more than one photographer riding along on the overflight would optimize the utility of the overflight.

Flight speed. Aircraft speed became an issue during this tabletop exercise. The Russian side requested that speed not exceed $200 \mathrm{~km} / \mathrm{hr}(\sim 160 \mathrm{knots})$ air speed. From an optics perspective, this is reasonable because observations on the ground blur for close-in viewing as speed grows. Both eyeball observation and photographs lose resolution with increased speed. Speeds greater than approximately 150 knots force the use of unacceptably high shutter speeds with reduced along-track image resolution. Thus, helicopters or high-lift fixed-wing aircraft will be the aircraft of choice in an OSI.

Data synthesis. There were difficulties in presenting ground-based visual and overflight data. Such data were voluminous and complex and required a great deal of concentration by the IT and extensive preparation by the data team. While some aspects of the presentations could be streamlined, this observation was not unique to the exercise, but represented an accurate simulation of the difficulty in presenting such data to the IT during a real field OSI. Each day, teams of 10 to 20 people would return to base camp, reporting their observations to the other members of the IT. How will they perform this task in a real OSI so that everyone is aware of the observations of other team members? It will be a monumental task to integrate this information, as was demonstrated in the exercise.

Additionally, it will be difficult to explain, via photographs, the distinguishing features that were seen either from the air or on the ground. The eye/brain combination is a far better tool than a two-dimensional photo. Consequently, rather than suggesting that the presentation of visual data should be improved for the exercises, a method ought to be developed instead to aid in synthesizing visual observation data with other forms of data collected during an OSI. 


\section{Ground-Based Visual Observation}

Documentation of visual observations. While there were many lessons learned in the U.S./RF Joint Tabletop exercises, one of the most pronounced was that an IT member, in reality, will be processing much more data collected with the eye than can effectively be conveyed during a simulation exercise, either verbally or with photus that are, of course, taken out of context. This emphasizes the subjective nature of visual observations and the necessity for inspectors to be well trained in the art of perception. Visual observations will have to be well documented to substantiate conclusions used to justify subsequent investigations and interpretation of all of the OSI data.

Visual observation expertise on ITs. The composition of the IT is crucial. For this exercise, the IT was composed of true experts in terms of recognizing nuclear explosion-related visual clues. For a real OSI, this high level of expertise may not be available if inspectors are drawn from many State Parties whose technical skills may be less well refined. The proper combination of expertise is necessary to conduct a thorough inspection.

Interviews. During the course of an inspection, an IT may wish to interview people in and around the inspection area and have informal interactions with ISP representatives, as was demonstrated in both exercises. While formal interviews may be very important, they may involve high-level ISP representatives who may not be knowledgeable enough to provide the details sought. Thus, the informal interactions that take place between the inspectors conducting a visual observation and their ISP escorts may provide the best information. But because interviewees are not always well-versed in either Treaty provisions or specific sensitivities at their site, they may inadvertently provide sensitive information that is unrelated to the purpose of the inspection. It is important, therefore, to strike a proper balance in granting inspectors the privilege of interviewing personnel in and around an inspection site, while protecting sensitive information.

Private property access. Access to private property was also an issue that emerged during the ground-based visual observations. While the Russian IT desired access to the medical isotope production facility, MedIsoChem, the "owner" of that facility felt that providing access to the facility could potentially compromise sensitive and proprietary information. This situation illustrated how visual observation could be hampered by legitimate lack of access. It will be necessary, therefore, to develop some protocol to deal with such situations should they arise during an actual OSI. 


\section{Passive Seismological Monitoring}

The objective of passive seismic monitoring during an OSI is to detect small-magnitude aftershocks from a possible underground nuclear explosion before their rate and magnitude decay to levels too small to detect. Seismic sensors need to be placed within $2 \mathrm{~km}$ of the source for adequate detection and identification. Thus, the task of the IT is to seismically monitor as much of the inspection area as possible in the shortest amount of time. This process can be greatly impeded by weather and terrain. In addition, other seismic sources such as local natural seismicity and mining activities have to be identified and located.

In this exercise, the Russian IT approach was to maximize the initial use of sensors. Toward this end, they immediately employed all of the 30 sensors available, (20 seismometers plus 10 spares) in a $4-\mathrm{km}$ grid, starting with the alluvial valley in the central part of the inspection area. 'The reasoning behind this approach was sound- aftershock rates decline most rapidly when a test is conducted in alluvium. Every two to three days, the Russian IT would relocate about one-third of the instruments to continue the systematic coverage of the grid, with the goal of covering the entire 1000 $\mathrm{km}^{2}$ inspection area. This grid deployment was particularly suited to the type of terrain (desert, mostly open country with good general access) in the U.S. scenario. The grid approach proved to be extremely effective because the Russian IT very quickly began detecting aftershocks from the UNE postulated for this scenario.

However, once a set of events had been detected (in this case from mining activities and from the UNE), the Russian IT chose not to focus on these areas to better characterize them and obtain more precise event locations. Rather, they allocated only a single seismic instrument from the predesigned grid pattern to monitor events coming from the mining ared and continued using the remaining instruments to further extend the grid coverage. This single instrument did not sufficiently supplement the detection capability to allow the team to obtain the precise locations, especially depth, needed to fully discriminate between seismic events related to active mining and aftershocks from a UNE. The Russian IT would have been able to identify the location of the UNE much more quickly and accurately if it had redeployed more than one station into the suspect area.

Seismic search strategy. While a grid-based search can be very effective given certain terrain conditions, an IT should also be very flexible in adapting to information as it is collected. Once a set of events is identified, sensors should immediately be deployed or redeployed to obtain a better characterization of those events.

The approach of the U.S. IT in the Russian scenario was quite different from that of the Russian

IT. Based on an initial assessment of the inspection area map, target areas of interest were identified and prioritized for sensor deployment. The initial deployment involved placing two to three sensors at each of five different sites of interest (none of which included the site of the UNE). Not all of the sensors available were initially deployed. This approach was partly dictated by the nature of the terrain: dense forest, few access roads, little outcropping rock, and many swampy areas. After the initial deployment, the U.S. IT realized that most of the data being received was local noise, but there were some events in the central part of the inspection area that looked suspicious. Additional sensors 
were then deployed in that area to obtain a better characterization. Eventually, sensors from other areas were redeployed until about 15 sensors were in place covering about a 5 to $10 \mathrm{~km}^{2}$ area. This allowed the U.S. IT to obtain a better understanding of the distribution of aftershocks and eventually to identify the hypocenter of the UNE within $400 \mathrm{~m}$.

The U.S. IT could have been more aggressive about the initial deployment of seismometers. Instead of waiting to obtain more information from the overflight or from visits to other sites, it would have been more advantageous to deploy as many sensors as quickly as possible. Because of the nature of the terrain, however, a grid-based approach would have been difficult to carry out in the Russian scenario. The importance of adapting the deployment strategy as information is gathered was aptly demonstrated by the U.S. IT experience.

Adaptation of search strategy. Quickly adapting the deployment strategy is also an important issue. Unforeseen differences in the Russian and U.S. approaches to structuring the exercise itself required changing the U.S. deployment strategy. The U.S. team initially expected that very local noise events at a site would be "discriminated" and not appear as events to a station, but the Russian control team assumed that discrimination was not possible and included them as events. This necessitated deploying additional instruments around a potential target and required that detections and locations be based on two or more stations. This eliminated the value of any single-station locations. Such a situation is realistic and requires rapid evaluation in the field by the seismologist and immediate changes to the deployment strategy.

Definition of spares. Another issue brought out by the passive seismic part of the exercise is that of the definition of spares. For this exercise, the U.S. and RF sides agreed beforehand that there would be a total of 30 seismometers available with associated data collection systems and telemetry units. Of these 30 , ten instruments were denoted as spares. However, during the play of the exercise, both sides agreed that all 30 instruments would be available initially for deployment. A definition of spares is not given in the treaty, but it could be taken to mean that a spare can only be used when a primary sensor is disabled. With that interpretation, there would have been a maximum of 20 seismic sensors available initially in the exercise, which would have important implications for a grid-based deployment strategy.

Effect of terrain on sensor deployment. Finally, it was clear from the exercise that the time needed for deployment of seismic sensors will be strongly dependent on the local terrain and weather conditions. In this exercise, both ITs were operating under almost ideal conditions (as agreed by both sides since play of logistics was not to be a major issue for investigation). The logistics of installing seismic stations and the base station for telemetry and processing will, in practice, have a very strong effect on the overall deployment strategy. In the U.S. experience, the Russian deployment strategy was very optimistic. In reality, the Russian IT would have found it difficult to deploy the instruments at the rate envisioned in their grid search strategy, to troubleshoot them for problems, and to retrieve the data using RF telemetry or physical retrieval. 


\section{Radionuclide Detection and Analysis}

The purpose of the radionuclide collection and analysis portion of the U.S./RF Joint Tabletop exercise was to search for the presence of "fresh," man-made radioactivity, interpret the source of this activity, and, if possible, date the origin of the activity. Together with visual and seismic information gathered in the inspection area, the radionuclide measurements were used to determine the likelihood of a clandestine nuclear test conducted by the ISP.

There were five kinds of samples to be analyzed (soil, water, swipes, subsurface gas, and atmospheric air) for the signature radionuclides listed in Table 1.

Table 1. Signature radionuclides permitted to be reported in an OSI Tabletop Exercise.

$\begin{array}{cccc}\text { "Particulate" isotope } & \text { Half-life } & \text { Noble gas Isotope } & \text { Half-life } \\ 95 \mathrm{Zr} & 64.0 \mathrm{~d} & 131 \mathrm{~m}_{\mathrm{Xe}} & 11.84 \mathrm{~d} \\ { }^{95} \mathrm{Nb} & 35.0 \mathrm{~d} & 133 \mathrm{~m}_{\mathrm{Xe}} & 2.19 \mathrm{~d} \\ 140 \mathrm{Ba}-140 \mathrm{La} & 12.75 \mathrm{~d}-1.678 \mathrm{~d} & 133 \mathrm{gXe} & 5.243 \mathrm{~d} \\ 141 \mathrm{Ce} & 32.5 \mathrm{~d} & 135 \mathrm{Xe} & 9.14 \mathrm{~h} \\ { }^{144} \mathrm{Ce} & 284.9 \mathrm{~d} & 37 \mathrm{Ar} & 35.0 \mathrm{~d} \\ 147 \mathrm{Nd} & 10.98 \mathrm{~d} & & \end{array}$

The principal analytical tool for radionuclide analysis for this exercise was gamma-ray analysis from both high-purity germanium (HPGe) and $\mathrm{NaI}(\mathrm{Tl})$ detectors. The NaI(Tl) detector was used on both overflight and ground-based surveys in the gross-activity mode, with no spectral information being used to identify radionuclides from their gamma-ray signature. HPGe detectors were used to identify radionuclides in the collected samples. The particulate isotopes could be observed in soils, water, swipes, and in atmospheric samples acquired by pumping air through a paper filter that was subsequently analyzed with a HPGe detector.

In the case of the noble gases, the samples were acquired in either of two ways: as subsurface samples, gathered by pumping on perforated metal stakes that had been pounded a number of meters into the ground or as atmospheric samples, collected by pumping air through cold traps and activated charcoal traps. In the latter case, the Xe noble-gas isotopes were physically separated from their elemental homologues and counted automatically, using beta-gamma coincidence techniques, in a unit built especially for the purpose. The ${ }^{37} \mathrm{Ar}$ samples had to be counted separately in an internal proportional counter due to the low energy of ${ }^{37} \mathrm{Ar}$ decay emissions.

In this exercise, the collection and analysis of these samples was notional (i.e., the processes were merely assumed to have taken place, but did not actually occur). The logistical aspect of the exercise was, for the most part, ignored, though some attempt was made to limit the number of samples 
that could be processed in any given inspection period to simulate what would be reasonably achievable with the equipment and personnel assumed to be available.

Alternative methods of sample analysis. The Russian IT introduced a mobile laboratory for the purpose of collecting and preparing samples for counting as the laboratory was being moved from the field to the Base Camp. This would reduce the average amount of time required for analysis of each sample. The U.S. team allowed the use of this vehicle, even though this vehicle had not appeared on the list of approved equipment. It was felt that while this innovative laboratory could be effective in relatively flat terrain where its travel would be relatively unimpeded, it would be severely limited in its mobility in rough and rugged terrain, such as that found in the U.S. scenario. The exclusive use of a mobile laboratory might limit samplc collection if sampling locations are far from one another, but could increase the expected analysis throughput since sample preparation can begin as soon as the sample is in the mobile laboratory.

Use of isotope ratios. In the development of the Russian scenario, the RF chose not to employ more complex radionuclide signatures, such as isotope ratios like $133 \mathrm{~m} \mathrm{Xe} / 133 \mathrm{~g} \mathrm{Xe}$, capable of identifying and dating source terms of the measured activity. The United States considers the identification of these source terms and their interpretation critical to the OSI mission, and therefore they should be exercised as fully as possible. The U.S. scenario provided for the measurement and reporting of isotope ratios, including $X e$ ratios and particulate radionuclide ratios, from a diversionary source (a nuclear reactor) just outside of the inspection area boundary. However, the Russian IT chose not to investigate this diversionary source, relying on seismic information to lead them to the critical location. They subsequently obtained subsurface gas samples and identified the location of the underground explosion from the presence of ${ }^{37} \mathrm{Ar}$ in these samples. Isotope ratios, although measured, were not utilized in the interpretation of this scenario.

Constraints on sample analysis. Certain radionuclide measurement characteristics (how long one must really count to achieve certain limits, for example) need to be examined in order to better understand the limits on sample preparation and counting. An effective result of gamma-ray (HPGe) analysis of a soil or water sample is either the actual activity of a given signature radionuclide (for example, $64-\mathrm{d}{ }^{95} \mathrm{Zr}$ ) or an upper limit of the activity of this nuclide if it cannot be definitely shown to be present (sometimes reported as the Minimum Detectable Concentration, or MDC). There is a tradeoff between the length of the counting interval (and the precision or MDC) and the number of samples that can be counted. This choice needs to be examined more closely both to understand the constraints in a real OSI as well as to simulate more realistically these situations in an exercise.

Noble gas systems. The current capability for collecting, purifying, and counting noble gas samples is largely unknown at this time. It is necessary to understand the kind of equipment that is commercially available or in need of development for noble gas sample treatment. Such equipment should be smaller and more portable than the Pacific Northwest National Laboratory Xe Automated Radioxenon Sampler/Analyzer IMS system used notionally in this exercise. 


\section{Logistics and Other OSI Operation Issues}

While both the United States and the Russian Federation agreed that logistical issues would not be a focus of this set of Joint Tabletop exercises, favoring instead to examine technical and operational OSI issues, some logistical issues inevitably arose. Some assumptions were needed regarding the amount of time needed to deploy instruments in various terrain, the capacity of various transportation equipment, and other parameters, to provide a realistic framework within which to conduct the exercises. It would be, for example, unrealistic that an IT could deploy all of its equipment in one day to any area of the inspection site. For the technical and operation lessons learned to be valid, the logistical constraints that an IT would face somehow needed to be simulated.

Although both sides agreed that some logistics needed to be taken into account, each side approached this differently, giving rise to some disagreements and providing an opportunity to explore some OSI logistics issues. This section will summarize some of those lessons learned as well as discuss other general OSI operation issues.

Instrument deployment times. While there is general understanding regarding the length of time required to deploy various instruments, more precise data need to be collected to fully comprehend the limitations that instrument deployment times will impose in successfully conducting an OSI. For example, the U.S. and Russian experiences differ with regard to the length of time required to seismically instrument an area. Understanding this more precisely could impact, for example, the choice of a search strategy in a given area. Likewise, deployment of radionuclide sampling equipment in the field would provide more precise data regarding the resources required to effectively monitor an inspection area. Such data could also greatly impact OSI planning and resource allocation by providing an IT leader with greater insight into which kinds of deployments and processes deplete existing resources most quickly.

Transportation. During this exercise, it also became clear that there was not agreement as to the capacity of various vehicles that would be used to field instruments and personnel. Again, such information is critical to understanding the limitations that an IT will encounter when in the field and how logistical constraints will impact the ability to capture the rapidly decaying phenomenology following any event likely to generate an OSI.

Logistical impacts of sample chain-of-custody. While it is understood that sample chain-ofcustody will need to be maintained for various types of samples, it is not yet clcar the degree to which this will impact the rate of data analysis during an OSI. When the procedures for chain-of-custody are fully developed, it will be necessary to examine the time delays that may be introduced into the sample collection and analysis process to understand how this may impact the conduct of an OSI.

Data management and decision-making. During the course of the exercises, it was evident that one of the most challenging aspects of an OSI was establishing a decision-making and data management process. Not only is it important that the IT have a data management computer program such as a geographic information system to organize the data by location, the IT also needs to determine, either in general or prior to a particular inspection, what criteria will be used in the decision-making process during the OSI. 


\section{OSI Strategy Lessons Learned}

The following section provides some insight into the various actions taken by each of the Joint Tabletop exercise teams as they simulated an IT or an ISP team, and attempts to reveal some of the factors that impacted the use of that particular team's strategy.

U.S. Inspection Team strategy. The U.S. IT used a focused search strategy, wherein even initial search activities were concentrated on areas, features, or facilities that a priori were judged to be of higher interest than other areas. Passive seismic sensors, radionuclide sensors, and soil gas collectors all were emplaced near features more likely, in the eyes of the U.S. inspectors, to be possible locations for a clandestine test. Even the initial overflight concentrated on portions of the inspection area that were judged a priori to have a higher probability of having hidden an illicit test.

The U.S. IT search strategy seemed to concentrate on facilities or features of subsections of the inspection area that were more similar to U.S. nuclear testing practices. That is, the U.S. IT tended to be more concerned with remote areas and mines, rather than with other venues or means by which the ISP might have conducted an illicit test. Ground search activities were not utilized as much as they could have been because U.S. nuclear testing generally occurred at the Nevada Test Site (NTS), which has few roads running through vast, unpopulated areas. Accordingly, the U.S. IT tended to downplay parts of the inspection area that were only accessible by unpaved roads through forests. In that regard, it also should be noted that forested areas may require close-spaced overflight tracks in order to fly directly over roads and partially cleared areas that might not be visible when viewed on a slant angle.

The U.S. IT placed heavy emphasis on preserving for subsequent utilization the portion of the treaty-prescribed 12-hour time that had not been used up during the first day or two. In essence, the U.S. IT considered that they were entitled to the full 12-hour flight time, regardless of when they chose to use it. In that sense, the U.S. IT seemed to consider that flight time not used up for "general familiarization" or "narrowing of the search area" could then be used for more direct data gathering, such as flying low-resolution NaI detectors over areas of specific interest. The Evaluation Team noted that, in their view, however, the Treaty negotiators' intent was for the "initial" overflight to be just that: literally a single overflight, save for whatever staging and refueling might be needed; that it be conducted very soon after arrival of the IT at the inspection area; that the permitted purpose was for general familiarization and narrowing of the search area; and that if the full 12 hours were not utilized initially, they could not be "banked" for later credit and withdrawal. Their view was that even the possibility of limited daylight hours, such as in high latitude areas, was not particularly important in terms of distributing the initial overflight over several days in order to obtain 12 hours of useful daylight time for flying.

Adverse weather conditions were not played out for the inspection due to the already severe time-constraints of this exercise. Yet weather, under both the RF and the U.S. scenarios could seriously hinder conduct of the OSI and could modify the IT's strategy. Rain or cloudy weather could have prevented overflights, slowing progress. In the Russian scenario, rain could have impeded travel over dirt roads. In both scenarios, snow cover could obscure any indications of past off-road travel and impede installation of instruments such as seismometers. 
The U.S. control team, in designing its scenario and in preparing to provide verbal descriptions of what ground or aerial inspectors might observe, tended to emphasize geological and geophysical features, consistent with the features more important to an OSI in a place like NTS.

Russian Inspected State Party (RF ISP) strategy. The RF ISP, like the U.S. ISP, was generally cooperative in granting permission to the IT to go to subsections of the inspection area. After the exercise concluded, however, the U.S. IT was informed that it would have been denied permission to go into certain areas; i.e., that restricted access zones, as allowed for in the Treaty, would have been declared and access by IT members would have been denied.

The RF ISP exercised its Treaty-prescribed prerogatives to take 36 hours at the POE in order to examine the equipment brought in by the U.S. IT, ostensibly to ensure that the equipment met technical specifications and did not provide additional sensitivities or other capabilities.

More generally, the RF ISP tended not to grant permission to the U.S. IT to do anything that was not explicitly permitted in the Treaty.

Russian IT and U.S. ISP strategies. In contrast to the initial, focused search strategy employed by the U.S. IT, the RF IT consciously chose a more systematic, grid-like, wide-area search strategy. Passive seismic sensors, radionuclide sensors, soil gas collectors, and even the initial overflight were initially spread widely over the entire $1000 \mathrm{~km}^{2}$ inspection area. Subsequent redeployments of each of those assets then became more focused in a gradual way.

The RF IT, like its U.S. counterparts, asked to use all 12 hours of overflight after its original grid search was completed, but did not insist when the U.S. ISP introduced a (relatively low) barrier by stating that the requested helicopter was not available for a few days. The U.S. ISP would have been willing, if the RF IT had persisted, to make available a fixed-wing aircraft four to five days later. In this regard, the U.S. ISP attempted to demonstrate some flexibility regarding the availability of the full 12 hours of overflight time beyond just the first couple of days, but called attention to the fact that aircraft are expensive to have "on call" and that fixed-wing aircraft are a permissible, if less useful, platform for OSI overflights.

The U.S. ISP, like its Russian counterparts, tended to be quite cooperative in terms of granting permission for the Russian IT to conduct its activities. The sensor deployment strategy of the Russian IT stressed the assumed U.S. ISP vehicle and escort capabilities, reflecting the more careful attention by the Russians and their computer model to using logistics capabilities to the maximum.

The U.S. ISP was particularly, perhaps even excessively, generous in allowing the RF IT to proceed to the inspection area without taking the full time allowed for examining the IT's equipment at the POE. While that allowed the exercise to start off on a note of cooperation and allowed the exercise to proceed more quickly (without much exercise time being consumed by POE activities), it may be unrealistic to expect an ISP not to examine OSI equipment carefully at the POE-both from the standpoint of suspicions of surreptitious data-gathering capabilities and from the standpoint of allowing the IT to arrive at the inspection area earlier when any aftershock activity is more likely to remain and be detectable. 
On several occasions, the RF IT delivered its data request- i.e., its requested inspection activities for the next exercise period--directly to the U.S. data team, rather than ensuring that the U.S. ISP would permit, or could logistically support, each of those inspection activities. During a real OSI, there would be no data team from which to request data, but there would be a real ISP that might or might not permit all requested IT activities. Similarly, the RF IT expected data to be returned to them for each day of an exercise period, rather than at the end of a multiday exercise period. While some data might be obtainable daily during a real OSI (e.g., telemetered seismic data), other data might not be available for several days (e.g., soil gas samples that must be collected for a several-day period).

The RF IT wished to have continuous video as well as occasional still photos during the overflight. However, since the Treaty says that the ISP shall have the right to provide its own camera operator, there may be only one person on the overflight allowed to take photos. Thus either video or stills may be possible at a given time, but not both. 


\section{Exercise Planning Lessons Learned}

In addition to providing a vehicle for understanding various technical and operational issues associated with CTBT on-site inspections, the U.S./RF Joint Tabletop Exercise was useful in gaining insight into the utility of such exercises as a tool for examining various OSI issues. As such, it also provided an opportunity to record some lessons pertaining to the implementation of tabletop exercises. This section will detail some of these lessons in two sections: the first discusses general lessons learned pertinent to exercise development and exccution, while the second discusses lessons related to data preparation and presentation.

\section{Exercise Development and Execution}

While any simulation exercise requires a great deal of planning and preparation to successfully execute, the planning and preparation required for any such exercise in a bilateral or multilateral setting will be significantly greater due to the many complexities that such an environment creates. While participants on each side may agree on the objectives of the exercise and even conceptually how it ought to be implemented, each side will have its own view as to how this is best accomplished. And, even though agreement will eventually be reached on these points, differences will still remain and not become evident until the actual execution of the exercise. This was perhaps the principal lesson learned through this exercise-planning experience.

In the course of this tablelop's development and execution, there were a number of instances in which participants failed to reach a complete understanding of issues, even when each side believed such issues to have been thoroughly explored and resolved. This section of the report will discuss what steps may be taken to minimize the possibility of such misunderstandings between fellow planning team members as well as some of the lessons believed to be relevant and useful to planners of subsequent CTBT OSI exercises.

Communication between planning team members. Much of the success of this exercise is owed to the extensive communication within the U.S. team as well as with the Russian planning team. While not all members of the U.S. and RF control teams met regularly, all of the subject matter experts who needed to communicate with their counterparts did so, usually via e-mail. Early in the planning phase of the exercise, participants established how they would communicate and what subjects would be communicated.

Designation of an alternate control team head. It is important that the primary coordinator on each side have a designated alternate who can be called upon in the event the primary exercise coordinator is not available, both to continue to interface with members in that team as well as with members of the other planning team.

Documentation of agreements made. In the preparatory phase of an exercise, it is vital to clearly document all of the meetings held and agreements reached among participants. This documentation should then be reviewed by all participants and checked for accuracy, since all team 
members will use these documents as reference materials when the scenario and supporting data are generated. One particular document developed by the control team was a set of operating assumptions, which detailed key elements that would assist in shaping the direction of the exercise. The operating assumptions included decisions regarding the role of the Evaluation Team, the scope of the exercise, the level of data processing that would have to be done by each IT, and others.

Exchange of data. At various times during the planning phase of the exercise, the U.S. and RF control teams exchanged data to verify data formats to be used during the exercise as well as to provide preliminary scenario data, such as the consultation and clarification $(\mathrm{C} \& \mathrm{C})$ package. While data exchanges to verify data formatting helped to minimize confusion between the teams, more extensive data exchanges should be done in the form of a limited "dry-run." The teams would use mock data to verify what kinds of data the teams would see during the actual exercise.

Additionally, since it would be impractical to do the same with the $C \& C$ package because it contains scenario information, each side could pass the $C \& C$ package to a third party, who could verify that the package contained all of the intended information, including maps with legends, images, and other supporting information. During this exercise, the U.S. team received an incomplete C\&C package, which inhibited their development of an inspection plan. There was no time to obtain the missing information prior to traveling to Russia since the joint U.S./RF control team had agreed, as part of the operating assumptions, that the $C \& C$ package exchange would take place shortly before the team departed, to simulate the length of time a real IT would have to develop an inspection plan.

Method of exercise implementation. Because this activity was planned as two exercises with a reversal of roles by the U.S. and RF sides in each exercise, there was an underlying feeling of competitiveness. This resulted in some intense periods in which certain aspects of genuine difficulty in data generation by the U.S. data team were misinterpreted by the Russian IT as delay tactics by the ISP. This also resulted in accelerated attention to certain areas as opposed to a more systematic approach to the inspection. While the method of implementation did not prevent the exercise from achieving its objectives, other methods of implementing bilateral tabletops could be explored that would minimize this feeling of competitiveness and allow both sides to focus more on the processes used by the IT rather than the results that they may achieve.

Role of exercise controller. The exercise controller's main function is analogous to that of the director of a play - this individual is responsible for ensuring that all participants understand and execute their roles at the appropriate time and that all are aware of the status of the exercise. The controller should be very familiar with the exercise scenarios but should not have any other role during the execution of the tabletop.

Time compression. While it is necessary to have some time compression in a tabletop exercise, that compression should not impede the ability of the exercise to evolve naturally and to reveal relevant issues. When time compression is too great, participants tend to rush through certain aspects of an exercise and become focused on getting through a minimum number of inspection days. This places the IT members in a state of mind not conducive to exploring the inspection area in a manner consistent with what would be done in the field and interferes with the natural evolution of the exercise. A compression of 2.5 days to simulate 25 days of an inspection is too great; four or five days would have provided a sufficient amount of time. 
Use of individual computers for data generation. Initially, the control team debated whether the U.S. side could bring its own computers or should rely on the Russian side to provide them. Finally, it was decided that certain data team members would bring their own. This proved to be very important for efficient data production. Data could be generated in the midst of discussions, in the back of the main room or elsewhere. In addition, data team members were intimately familiar with data sets, application software, and operating systems, which permitted rapid data production and analysis. The decision to allow U.S. team members to bring their own computers was crucial in assuring the success of this exercise.

Playing logistics in a tabletop exercise. An innovative approach to track logistics used by the $\mathrm{RF}$ in their scenario was a computer program designed for a number of bookkeeping tasks. Based on a digitized map of the RF inspection area, this program kept track of overflight and ground-based visual observations, vehicle movement, sampling locations, and seismic sensor placement. This program substantially facilitated the exchange of information between the ISP and the IT. Future improvements and additions to the program could result in greater emphasis on the logistical aspects of an exercise such as the metering of travel time, the allocation of personnel, and their use in the field according to their specific skills. Such a program could ensure that the resources (time and equipment) and the limited number of personnel with specific skills were actually available to perform specific tasks. In addition, aspects of an OSI such as weather and the results of sample analyses or seismic sensor readings could be played out more efficiently.

\section{Data Preparation and Presentation}

Presentation of overflight data. The U.S. data team presentation of overflight observations was done via text, not photographs. Text permitted rapid creation of data without the concomitant questions raised with photographs. This worked well because relevant data could be excerpted from the prepared materials. The presenter could be asked questions about any portion of the inspection area and could add extra clues or withhold information, depending on what was deemed appropriate at that time.

Use of photos and schematics to convey ground-based visual observations. The ground-based visual data, as presented by the Russian side, relied heavily on photographs. This resulted in the U.S. IT asking many questions that were unrelated to the information that the presenter intended to convey, but instead were unique to the photo being displayed. While some photos can be invaluable for informing exercise members of the terrain they will be entering, too much dependence upon photos may be deleterious to the exercise. Schematics, alternatively, provided minimal information, but seemed to speed up the exercise, offering the chance to ask questions about features more relevant to the IT's investigation.

Improving visual data presentation. While the current methods used to convey visual observation data have been found to be the most effective, they are also very time consuming. Alternative methods have been explored but would require a substantial amount of development to become applicable to CTBT OSIs. One alternative for conveying data more quickly would be to have a number of inspection activities proceeding simultaneously during the course of the exercise. For example, some members of the IT could listen to the visual observation data presentation, then summarize it for the remainder of the team. This would also simulate more realistically how an infield exercise would proceed. 
Automation of seismic data generation. During previous tabletop exercises, processing of seismic data was carried out manually. This proved very time-consuming and was a limiting factor in the play of the exercise. For the joint U.S./RF tabletop exercise, computer programs were used that greatly improved data processing. The U.S. data team also provided a printout of daily event catalogs and plots of event locations, which aided the Russian IT in its analysis and interpretation of the data. The turnaround time, however, for the U.S. data team to produce the data was limited by another factor-the time it took to cross-check the deployment logistics. For each exercise period, the Russian IT would provide the U.S. side with a list of new locations for seismometers, which had to be checked to determine how long the deployments (or redeployments) would take. This process, which was done manually by the U.S. data team, took at least 30 minutes for each exercise period. The final seismic data could not be produced until all of the sensor locations were known, so the logistical evaluation of the installation became a limiting factor in the data team response.

This was not an issue for the Russian side because travel and installation time calculations were built into their computer program. It would be beneficial for future exercises for the United States to develop an automated system for determining travel times within the inspection area and times for instrument deployment, set-up, and testing. In addition, neither the U.S. nor the Russian side included time for setting up the seismic base station telemetry and analysis equipment.

Seismic data format. Initially, the Russian side wanted to have the IT determine event locations from raw $\mathrm{P}$ and $\mathrm{S}$ wave time pick data provided by the data team. The resulting event locations, determined by the IT using a computer code for hypocentral determination, would automatically include the uncertainty introduced by station distributions, picking errors, and the earth velocity model used, as would be the case in a real exercise. While this approach provides maximum realism, the U.S. data team convinced the Russians that such an approach was not practical because of the time needed for the data team to generate travel time data and the time needed by the IT to process the data. During each period for which a new arrangement of seismic stations was in place, the data team would need to produce a complete set of compressional and shear wave arrival times for each simulated event at each detecting seismic station, with consideration of picking errors based on signalto-noise ratios and the seismic velocity model for the inspection area. The U.S. IT would then have to run all of this data through a location code with some assumed velocity model to determine the locations of the detected events.

Since data analysis was not considered to be a goal of this exercise, the control team decided that, even with the use of computers, having the IT analyze data would require too much time and divert attention from the stated objectives of the exercise. In addition, the U.S. control team had insufficient time and resources to automate the exercise and coordinate the computer code with the Russian counterparts. It was finally agreed that for each exercise period, the data team would use a set of predetermined event locations and the current station configuration to compute a set of detected events with built-in location uncertainties. No data processing would be required of the IT.

During a meeting prior to the exercise, the U.S. and Russian sides agreed on most of the important aspects of seismic data processing (e.g., attenuation rates to use for seismic signals, aftershock occurrence rates from explosions, calibration of sensor signal strength to magnitude, signalto-noise ratios for delection and identification, formats for data oulput, etc.). However, since both 
sides were still developing the computer codes for seismic data processing when the meetings took place, there inevitably were some differences that arose during the exercise. For example, as a result of the U.S.-only dry-run exercise held before going to Russia, the U.S. data team decided to include a tabular listing of the detected events and a map of the event locations; this greatly reduced the time needed by the IT for seismic data analysis. During the exercise, the Russian data team did not provide the U.S. IT with either a table or location map of the detected events; this added greatly to the time needed for data analysis by the U.S. IT.

In future exercises, it would be beneficial to verify data formats, in detail, prior to the start of the exercise. This could be accomplished by allocating a short period of time during which several data exchanges could take place between data team members and IT members, utilizing mock data. This would preferably be done several weeks in advance of the exercise to allow for modifications of data generation systems.

Simulating the effect of noise in seismic monitoring. The most substantial difference between the U.S. and Russian simulation of seismic data in the exercise was in the manner in which seismic noise was handled. The U.S. data simulation assumed that an automated system or analyst would be able to eliminate most nonnatural noise sources local to a single station (such as heavy equipment passing the sensor or heavy machinery operating nearby). Thus, for the purpose of the exercise, an event detection reported by the data team would be considered to be a real seismic event such as an earthquake aftershock, mine explosion, or explosion aftershock and not local noise, even if it were detected by only a single sensor. The Russian data team, however, took a different approach. In their scenario, the Russians wanted to simulate difficulties that could arise from locally generated noise (intentional or otherwise). Hence, the bulk of the "detected" events were single-station detections, indicating a very local source. The only "real" seismic events (aftershocks from the UNL) were events detected by multiple stations. Once the U.S. IT understood this aspect of the data generated by the Russian data team, it was relatively easy to identify the source of aftershocks.

The U.S. control team does not believe that this is a very effective way of simulating the effect of noise. Some of the "local" noise events of the Russian scenario were of relatively large magnitude $(0.5-1.0)$. Events of this size should have been detected over a large portion of the inspection area, not just by a single station. Hence, this part of the simulation was not realistic. By frequency analysis or by simple visual inspection, an experienced seismic analyst would normally determine that such large local events were not local noise.

Use of ${ }^{37} \mathrm{Ar}$ in tabletop exercises. ${ }^{37} \mathrm{Ar}$ is produced almost exclusively by the interaction of high-energy neutrons with natural calcium in the surrounding medium of a nuclear test. As such, it is virtually a "smoking gun" for the identification of a violation of the CTBT. Although the actual transport of ${ }^{37}$ Ar by "barometric pumping" from the detonation point underground to the surface may take months, it is tempting to generate an ad hoc presence in the exercise (e.g., a pressurized leak, employed by both sides in this exercise) to construct a simpler and more definite signature of violation. Consequently, the removal of ${ }^{37} \mathrm{Ar}$ as one of the "reportable" radionuclides should be considered for OSI exercises in order to require the generation and subsequent interpretation of complex radionuclide signatures that would excrcise more realistically the steps an IT would need to take in an OSI. Such interpretation of possibly ambiguous radionuclide signatures may be necessary to complete the mission of an actual OSI, whether a clandestine nuclear test has been executed or not. 


\section{Report of the Evaluation Team}

The U.S./RF Joint Tabletop exercise participants included two Russian and two U.S. evaluators who observed and evaluated the exercise. The Evaluation Team members were selected because of their technical expertise, as well as their strong first-hand knowledge of testing issues, the CTBT negotiations, and Provisional Technical Secretarial (PTS) discussions regarding the CTBT verification regime. The Evaluation Team provided a written statement containing its collective assessment of the conduct of the exercise. Five additional U.S. observers, representing the Department of Energy (DOE), the Arms Control and Disarmament Agency (ACDA), and the Department of State, also attended the exercise and provided their observations to the group informally. The following evaluation is based primarily on the report by the Evaluation Team. However, it includes input provided by the Observers as well.

The team based its evaluation on the four objectives of the exercise:

- To simulate the actions of the IT, including interactions with the ISP, in order to examine different ways the U.S. and RF approach inspections and develop appropriate recommendations for the international community.

- To identify ambiguities and contradictions in the interpretation of Treaty and Protocol provisions that might become apparent in the course of an inspection and that need clarification in connection with the development of Operational Manuals and OSI infrastructure.

- To confirm the efficacy of using bilateral tabletop exercises to assist in developing an effective CTBT verification regime.

- To identify strong and weak points in the preparation and implementation methods of such exercises for the purpose of further improving possible future exercises.

The Evaluators and Observers concluded that the tabletop exercise succeeded in achieving its objectives. It illuminated a number of practical issues that will arise during actual on-site inspections under the CTBT. The lessons learned will help the United States and the Russian Federation prepare for implementation of the Treaty and lay the groundwork for further bilateral cooperation in this field. The group recommended that the experience gained from the exercise be shared with the CTBT Preparatory Commission, in Vienna, to help it prepare to implement the on-site inspection regime in the Treaty, including inspector training, Operational Manual preparation, and equipment selection.

The Evaluators commented that the scenarios used in the exercise were challenging without being overly complicated, allowing both sides to practice several aspects of real inspections. An appropriate amount of detail was provided, and the scenarios were internally consistent. At the same time, the Evaluators noted that in future exercises, the control teams should better define the ground rules and basic assumptions that will be used. Further, these assumptions should be clearly agreed upon in advance and recorded in written form. In this exercise, the sides appeared to begin the exercises with 
different assumptions regarding certain elements, including background seismic noise, equipment to be used, and certain logistical constraints.

The exercise highlighted the importance of precision and clarity in communications between the IT and the ISP team. When more than one language is used, the availability of high-quality interpretation is essential. Even with the relative simplicity of this excreise and the scrvices of excellent interpreters, a few misunderstandings and delays occurred due to communication problems. In an effort to improve communication, the Evaluators recommended that in future bilateral exercises, the U.S. team should provide at least one interpreter who is a native English speaker. In addition, all interpreters should be trained for technical as well as nontechnical interpretation.

In this exercise, the amount of information initially supplied to the IT slowed the beginning of the exercise. It would be more realistic for the team to have in its possession not only the information developed during the $C \& C$ process and the debate in the Executive Council, but also the information that would presumably be supplied by the Technical Secretariat-maps of the region, for example, the location of all operating nuclear reactors in the area, and perhaps relevant unclassified satellite imagery.

The exercise confirmed that the duration of the exercise and rules imposed influence the effectiveness of the simulation process and decision-making. In some cases, the time compression imposed during the exercise prevented the IT from thoroughly considering data and developing a unified deployment and sampling strategy. In the future, exercises of a similar scope should be allotted at least four days.

Further work should be done to achieve greater realism in the exercise wherever possible. In particular, it would be useful to exercise logistical issues that could arise during an on-site inspection. For example, future exercises could address issues associated with the geographic separation of subgroups, communications, chain of command, equipment failures, illness, inclement weather, and unexpected logistical problems.

Similarly, the interactions between the IT and the ISP were played out in this exercise in a highly cooperative manner, which was appropriate for this stage of our work. As a result, the focus was primarily on data collection and interpretation, rather than on negotiation. In future exercises, we may wish to consider more adversarial scenarios, in which negotiation and compromise play a greater role. It would also be useful to further practice interviewing techniques, including those for dealing with uncooperative or untruthful subjects.

The concepts of operations used by the two sides were effective in gaining relevant information within the constraints imposed by the scenarios. Both ITs divided themselves roughly into visual observation and seismic and radionuclide subgroups and operated efficiently. There were differences in approach, however. For example, the U.S. side used a cautious initial approach, both in the use of its initial overflight and the targeted placement of a few sensors near suspect sites. The Russian side, alternatively, decided to cover, as soon as possible, the entire Inspection Area on its initial overflight and to deploy the maximum number of fixed seismic sensors. In both scenarios, the IT discovered the suspect explosion toward the end of the exercise. 
The Evaluators noted that seismic and radionuclide sensors and data lend themselves well to simulation. The simulation of visual information and the use of such simulated information, obtained from overflights and ground-based observation are much more difficult. In this exercise, the latter was rather time-consuming and not entirely realistic, despite the best efforts of the participants. Realistic exercises in this area may require very elaborate and expensive simulations or perhaps must await exercises in the field. The Evaluators and Observers strongly recommended that the group investigate better approaches to presenting visual information to facilitate future exercises. One manner in which to assist with visual observation is to ensure that the IT is provided with maps of the region, the location of all operating nuclear reactors in the area, and perhaps relevant unclassified satellite imagery prior to the exercise. In addition, visual descriptions of areas could be presented in written form, and the IT members could respond to that information and request clarification when needed. One observer suggested that the IT chief provide the rest of the IT with a report (provided by the control team) at the end of each inspection day that would describe the main areas of interest observed by the visual observation team. This option would also more realistically simulate an actual inspection.

One of the most useful benefits of realistic simulations is the identification of problems related to differing interpretations of, or lack of clarity in, the Treaty. A few such issues arose, such as whether the initial overflight could be spread out over several days. It is important that such issues be identified and resolved in Vienna before Entry into Force of the Treaty.

The exercise also highlighted differences in interpretation of the types of equipment that would be used during an on-site inspection, for example, a mobile laboratory. Although no equipment was rejected by the ISP during this exercise, it seems evident that equipment issues such as certification, calibration and registration should be worked out to the maximum extent possible in Vienna, to minimize problems and delays related to equipment at the POE. In addition, it should be made clear in advance what equipment (for example, means of transportation) will be provided by the ISP at the POE and in the Inspection Area.

In this exercise, both ITs presented a brief verbal report to simulate their report to the Executive Council. In a longer, more realistic exercise, a detailed written report would be required.

\section{Recommended Next Steps}

The Evaluation Team recommended that another bilateral exercise should be held as soon as it can be properly prepared. It should incorporate lessons learned from this exercise, as well as greater realism. The sides should also move toward cooperative work using real instrumentation in the field. The eventual goal should be realistic multilateral trial inspections. 


\section{Proposed Next Steps for U.S./RF Interactions on CTBT OSI}

The Exercise Evaluators and Observers determined that the U.S./RF Joint Tabletop exercise was valuable in highlighting policy, technical, and procedural issues that require resolution both within each national government and within the PTS. It also allowed participants the opportunity to work through certain technical issues and operational details associated with on-site inspections in a cost-effective manner. Because of the value and success of the exercise, it is expected that this Joint Exercise was the first in a line of efforts of this type. Future activities would occur under the auspices of Working Group III. The group identified three possible next steps, as noted below.

Additional Bilateral Tabletop Exercises. For the RF participants, this exercise was the first such effort in which they were involved. Future exercises should build on this experience. Through the development and implementation process of this exercise, the participants learned a great deal about conducting an effective tabletop exercise. The exercise highlighted policy, technical, and operational issues that need to be resolved before the CTBT Prepcom completes the On-Site Inspection Operations Manual. Additional tabletop exercises would provide an opportunity to flesh out such issues. Future exercises should address such issues as logistics, a confrontational or intransigent ISP, equipment failures, managed access, inspector illness, difficult weather conditions, and the continuation phase on an on-site inspection.

Multilateral Tabletop Exercise. The group noted that the PTS would benefit from an exercise like the one conducted jointly with Russia. Such an exercise would provide participants with an opportunity to identify and resolve policy, technical, methodological, and logistics issues associated with conducting an on-site inspection. It is worth considering conducting a multilateral tabletop exercise in which members of the PTS would participate as inspectors. U.S. and Russian policy and technical experts could serve as the Control Team for such an exercise or could participate as inspectors, as well.

Directed Field Exercises. The tabletop exercise made clear that adequate OSI procedures cannot be established until an equipment list is agreed, and there is a thorough understanding of the logistics associated with CTBT on-site inspections. Seismic monitoring, radionuclide sampling and visual inspections each have associated with them specific logistical requirements and limitations. To address these issues in a cost-effective manner, the United States and Russia could hold their own internal directed exercises that isolate specific methodologies and technologies. At an appropriate time, policy and technical experts should build on these field exercises by conducting bilateral field exercises that would enable participants to refine methodologies and techniques. 


\section{Appendix I}

RF Scenario Consultation and Clarification Package 


\section{CTBTO \\ The Comprehensive Test-Ban Treaty Organization}

Vienna International Centre, P.O. Box 1200, A-1400 Vienna, Austria. Tel: (+43-1) 213456200. Facsimile: (+43-1) 21345 5898. E-Mail: Official DGOTS@CTBTO.org.

\section{CTBTO RESTRICTED}

Form Number: F06

FROM: Comprehensive Test-Ban Treaty Organization

TO: Pacifica

Precedence: Immediate

Subject: Request for Clarification

1. CTBT/OTS/1500/1427/2001/006/F06

2. REFERENCE: NONE

3. CONTENT: At 0800 on 6 November 2001, the CTBTO received the following Request for Assistance in clarifying a matter of CTBT concern from Atlantia:

A. Pursuant to Article IV.C. paragraph 32, Atlantia requests the Executive Council to assist in clarifying a matter which causes us concern about possible noncompliance with the basic obligations of the Comprehensive Test-Ban Treaty by Pacifica.

B. On 1 November 2001 at 1215, the International Monitoring System detected IDC Event 1614221, a 3.6 magnitude seismic event in the vicinity of $36.8217 \mathrm{~N}$ 166.3091W detected at a depth of less than five (5) kilometres.

C. Possibly related to this event, increased levels of ambiguous activity, including tunneling, has been detected, utilizing commercially-available satellite imagery, at underground facilities in the vicinity of IDC Event 1614221.

D. Request immediate consultation and clarification with Pacifica to resolve this concern about possible noncompliance.

4. REMARKS: NONE

5. End of CTBT/OST/1500/1427/2001/006/F06 


\section{CTBTO \\ The Comprehensive Test-Ban Treaty Organization}

Vienna International Centre, P.O. Box 1200, A-1400 Vienna, Austria. Tel: (+43-1) 213456200.

Facsimile: (+43-1) 21345 5898. E-Mail: Official_DGOTS@CTBTO.org.

\section{CTBTO RESTRICTED}

Form Number: F07

FROM: Comprehensive Test-Ban Treaty Organization

TO: Atlantia

Precedence: Immediate

Subject: Response to Request for Clarification

1. CTBT/OTS/1510/1452/2001/008/F07

2. REFERENCE: CTBT/OTS/1500/1427/2001/006/F06

3. CONTENT: At 1325 on 8 November 2001, the CTBTO received the following Response to the Request for Clarification from Pacifica:

A. In response to the compliance conccrn stated in the reference, the Government of Pacifica is currently investigating a possible source of IDC Event 1614221. An unintentionally large chemical explosion has been reported at a commercial surface coal mine at the same time and in the vicinity of the IDC Event. Initial reports indicate that personnel at this coal mine, located at $36.87 \mathrm{~N} 166.30 \mathrm{~W}$, had planned a ripple-fire explosion in the course of routine mining activity, but for a currently unknown reason, inadvertently detonated all explosives simultaneously.

B. An additional possibility for the seismic event recorded as IDC Event 1614221 could have been an aftershock of the magnitude 4.1 earthquake that occurred in the vicinity (36.985N 166.230W) on 6 October 2001. (See IDC Event 1609923.) Pacifica possesses no regional seismic capability, and is therefore, unable to confirm or refute this hypothesis.

C. A local media report of the magnitude 4.1 earthquake is appended as Attachment One.

D. The current activity referred to in the Reference as "anomalous activity" is normal mining activity related to several commercial mines in the region.

E. Pacifica also draws attention to the fact that no other component of the IMS detected any evidence of noncompliance, including two Atmospheric Radionuclide Stations within 500 kilometres and an Infrasound station within 300 kilometres of the area of IDC Event 1614221.

4. REMARKS: NONE 
5. End of CTBT/OTS/1510/1452/2001/008/F07.

\section{CTBTO RESTRICTED}




\title{
CTBTO RESTRICTED
}

\author{
Capital City Tribune \\ 8 October 2001
}

GOLD CITY: A moderate earthquake was felt by many city residents here on Saturday, although no injuries or significant property damage were reported. There were several reports of broken windows and dishes knocked from shelves. Seismologists at the National Earth Science Society in Capital City said the trembler registered a magnitude of 4.1 on the open-ended Richter scale and was centered in the Rhyolite Mountain area. Several long-time Gold City residents said this earthquake was one of the strongest in recent memory, although the area is known to frequently produce earthquakes in the magnitude 3 range.

\section{CTBTO RESTRICTED}




\section{CTBTO \\ The Comprehensive Test-Ban Treaty Organization}

Vienna International Centre, P.O. Box 1200, A-1400 Vienna, Austria. Tel: (+43-1) 213456200.

Facsimile: (+43-1) 21345 5898. E-Mail: Official DGOTS@CTBTO.org.

\section{CTBTO RESTRICTED}

Form Number: F08

FROM: Comprehensive Test-Ban Treaty Organization

TO: Pacifica

Precedence: Immediate

Subject: On-Site Inspection Request

1. CTBT/OTS/0325/1460/2001/009/F08

2. REFERENCES: A. CTBT/OTS/1500/1427/2001/006/F06

B. CTBT/OTS/1510/1452/2001/008/F07

3. CONTENT: At 0135 on 9 November 2001, the CTBTO received the following On-Site Inspection Request from Atlantia:

A. Atlantia has thoroughly analyzed the data provided in the Pacifica Clarification Response and deems it unsatisfactory.

B. Atlantia believes activities possibly associated with the detected seismic event are sufficiently ambiguous to warrant this On-Site Inspection Request to clarify whether a nuclear weapon test explosion or other nuclear explosion has been carried out in violation of Article I of the Treaty.

C. Pacifica's allegation in Reference B that either an inadvertent chemical explosion or an earthquake aftershock caused IDC Event 1614221 lacks scientific basis.

D. A chemical explosion in a surface mine registering as a magnitude 3.6 event is highly unusual, even in a mining region that frequently uses blasting. Such an explosion would require a quantity of explosives far in excess of any known mining practices for this procedure. Additionally, the IMS infrasound station 300 kilometres away would have detected a surface explosion, as large as the one claimed by Pacifica.

E. The Pacifica hypothesis that IDC Event 1614221 could have been an aftershock of an earthquake that occurred 26 days earlier is marginally credible. However, analysis of this event has determined that the first arrival was a sharp upward moving wave indicative of an explosive event and not resembling an earthquake or its aftershock. 
F. The attached map of the proposed inspection area (Attachment One) shows it as a 1000 kilometre area that includes $36.8217 \mathrm{~N} 166.3091 \mathrm{~W}$, the location of IDC Event 1614221.

\section{REMARKS: NONE}

5. End of CTBT/OTS/0325/1460/2001/009/F08

\section{CTBTO RESTRICTED}




\section{CTBTO \\ The Comprehensive Test-Ban Treaty Organization}

Vienna International Centre, P.O. Box 1200, A-1400 Vienna, Austria. Tel: $(+43-1) 213456200$.

Facsimile: (+43-1) 21345 5898. E-Mail: Official DGOTS@CTBTO.org.

\section{CTBTO RESTRICTED}

Form Number: F09

FROM: Comprehensive Test-Ban Treaty Organization

TO: Pacifica

Precedence: Immediate

Subject: Director-General Request for Clarification

1. CTBT/OTS/0630/1462/2001/009/F09

2. REFERENCES: A. CTBT/OTS/1500/1427/2001/006/F06

B. CTBT/OTS/1510/1452/2001/008/F07

C. CTBT/OTS/0325/1460/2001/009/F08

3. CONTENT: Pursuant to Article IV.D. paragraph 42 of the Treaty, the Director-General seeks clarification specified below in order to clarify and resolve the On-Site Inspection Request received from Atlantia (Ref. C.):

A. Provide explanations and other relevant information in order to clarify the source of the seismic event known as IDC Event 1614221.

B. Provide explanations and other relevant information to clarify and resolve the ambiguities posed by the Requestor in Reference $\mathrm{C}$.

4. REMARKS: NONE

5. End of CTBT/OTS/0630/1462/2001/009/F09.

\section{CTBTO RESTRICTED}




\section{CTBTO}

\section{The Comprehensive Test-Ban Treaty Organization}

Vienna International Centre, P.O. Box 1200, A-1400 Vienna, Austria. Tel: (+43-1) 213456200.

Facsimile: (+43-1) 21345 5898. E-Mail: Official DGOTS@CTBTO.org.

\section{CTBTO RESTRICTED}

Form Number: F10

FROM: Comprehensive Test-Ban Treaty Organization

TO: All States Parties

Precedence: Immediate

Subject: Response to Director-General Request for Clarification

1. CTBT/OTS/0550/1488/2001/012/F10

2. REFERENCES: A. CTBT/OTS/1500/1427/2001/006/F06

B. CTBT/OTS/1510/1452/2001/008/F07

C. CTBT/OTS/0325/1460/2001/009/F08

D. CTBT/OTS/0630/1462/2001/009/F09

3. CONTENT: At 0405 on 12 November 2001, the CTBTO received the following Response to Director-General Request for Clarification from Pacifica:

A. Pacifica cannot offer "scientific" proof to back up our claim of an explosion at the coal mine since the region is seismically uncharacterized and we do not currently possess the technology to seismically monitor the region. Our investigation has determined the explosion was caused by human error. However, we can only offer the newspaper article, included as Attachment One, as further substantiation.

B. The lack of infrasound detection of the coal mine explosion is entirely feasible and readily explainable. The topography between the site of the explosion and infrasound station is uneven and, at the time of the explosion, rain showers were reported between these sites.

C. As stated in Reference B, Pacifica reiterates that the activity in the area is wholly unambiguous and solely related to commercial mining activities.

D. While Pacifica understands how an unsanctioned and uncoordinated large chomical explosion could enhance the ambiguity of this event, the obvious commercial mining activities in the region by no means reflect evidence of a violation under Article One of the CTBT. Compliance with the Treaty is an obligation this nation takes extremely seriously.

\section{REMARKS: NONE}


5. End of CTBT/OTS/0550/1488/2001/012/F10

CTBTO RESTRICTED 


\title{
CTBTO RESTRICTED
}

\author{
Capital City Tribune
}

10 November 2001

GOLD CITY: The mysterious rumbling felt by many here on November 1st was a nearby explosion, not another earthquake. A Pacifica Minerals spokesman reported at a press conference yesterday that workers at the company's open-pit coal mine near Gold Valley accidentally detonated "an abnormally large quantity of explosives" during routine mining activities. No deaths or injuries were reported at the mine, but an expensive drill rig was damaged. The spokesman said miners usually detonate smaller quantities to break up coal deposits in what is called "ripple-fire," but for some unknown reason, the explosives detonated simultaneously. An investigation is underway to determine the cause of the explosion.

\section{CTBTO RESTRICTED}




\section{CTBTO}

\section{The Comprehensive Test-Ban Treaty Organization}

Vienna International Centre, P.O. Box 1200, A-1400 Vienna, Austria. Tel: (+43-1) 213456200.

Facsimile: (+43-1) 21345 5898. E-Mail: Official DGOTS@CTBTO.org.

\section{CTBTO RESTRICTED}

Form Number: F11

FROM: Comprehensive Test-Ban Treaty Organization

TO: Pacifica

Precedence: Immediate

Subject: Notification of Inspection

1. CTBT/OTS/0105/1492/2001/013/F11

2. REFERENCES: A. CTBT/OTS/1500/1427/2001/006/F06

B. CTBT/OTS/1510/1452/2001/008/F07

C. CTBT/OTS/0325/1460/2001/009/F08

D. CTBT/OTS/0630/1462/2001/009/F09

E. CTBT/OTS/0550/1488/2001/012/F10

\section{INSPECTION MANDATE:}

A. Executive Council Decision: On 13 November 2001, the Executive Council resolved (with a vote of 46 members present $=32$ affirmative $/ 11$ negative $/ 3$ abstentions) that the request by the requesting State party (Reference $B$ ) is justified and hereby approves the On-Site Inspection Request to clarify whether a nuclear weapon test explosion or any other nuclear explosion has been carried out in violation of Article One of the Treaty in the area specified in C. below. Coincident with the carrying out of this mandate, the inspection team shall transmit a progress inspection report to the Executive Council through the Director-General no later than 8 December 2001.

B. Statc Party to be Inspected: Pacifica.

C. Location of Inspection Area: $1,000 \mathrm{KM}^{2}$ area including $36.8217 \mathrm{~N} 166.3091 \mathrm{~W}$ with boundaries in accordance with those drawn on the attached map (Attachment One).

D. Planned Types of Activity: Those activities specified in Part II. D. paragraph 69 (a) through (e).

E. Point of Entry: Capital City, Pacifica.

F. Transit or Basing Points: N/A

G. Head of the Inspection Team: NOTIONAL 
H. Members of the Inspection Team: NOTIONAL 39-persons

I. Proposed Observer: NOTIONAL

J. Equipment to be Used: (From the Agreed-Upon List.)

4. DATE AND ESTIMATED TIME OF ARRIVAL AT POINT OF ENTRY: 15 November 2001, 0835.

5. MEANS OF ARRIVAL AT POINT OF ENTRY: National Airlines Flight 0977.

6. EQUIPMENT AND SERVICES REQUESTED THE INSPECTED STATE PARTY TO MAKE AVAILABLE TO THE INSPECTION TEAM:

Hotel-like accommodations

Office space with electrical power and heat

Work area in inspection area for equipment checks and maintenance

Xerox-type reproduction machine

Required paper and assorted office supplies

Food service and water with transportable potable water containers

Access to medical services, if necessary

Suitable transportation for inspection personnel and equipment

34 12-volt automotive batteries

Required fuels and lubricants

7. REMARKS: Estimate 400 cubic metres at 33,000 kilograms of approved inspection equipment and personal baggage arriving with inspection team at the point of entry.

8. End of CTBT/OTS/0105/1492/2001/013/F11.

\section{CTBTO RESTRICTED}




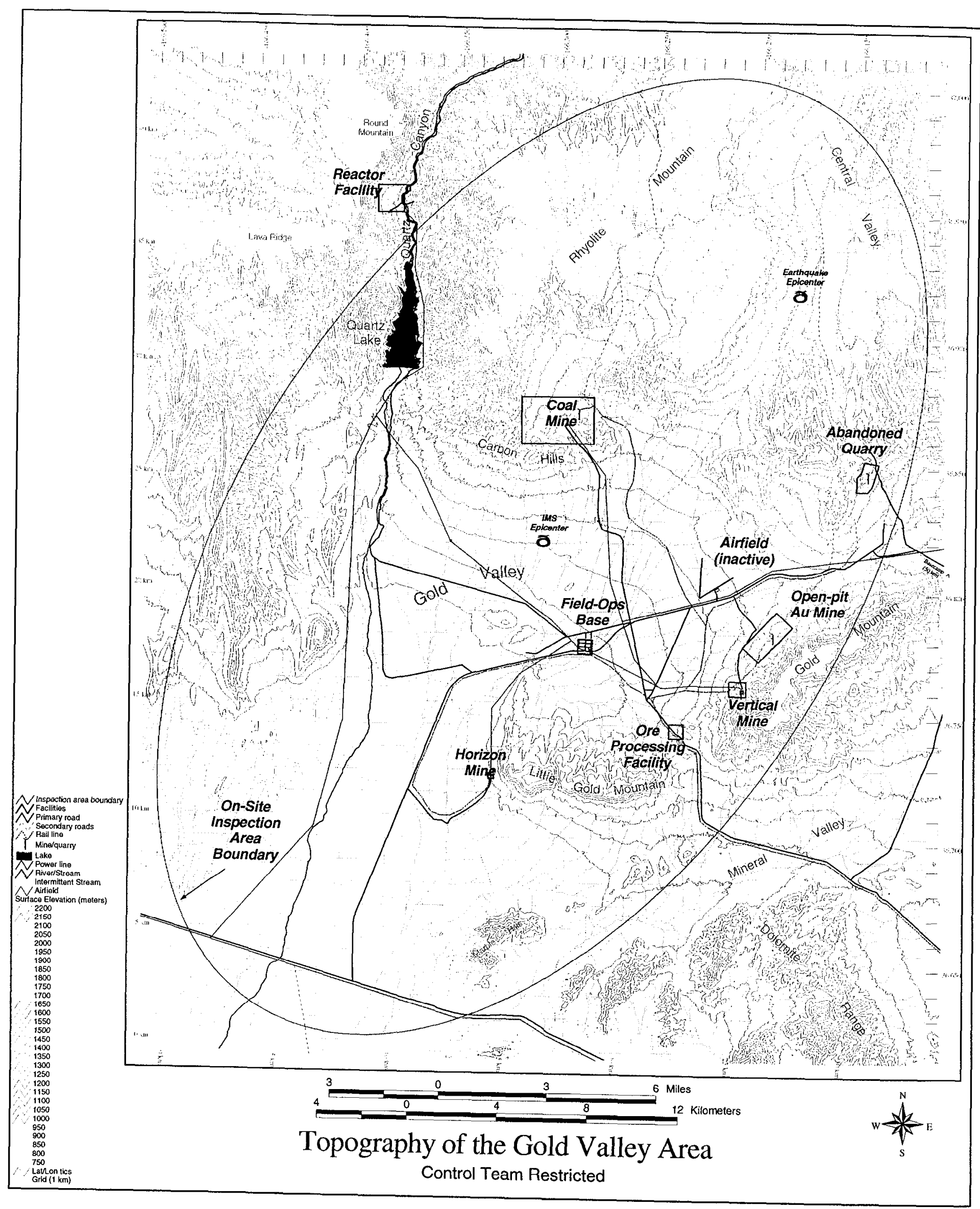




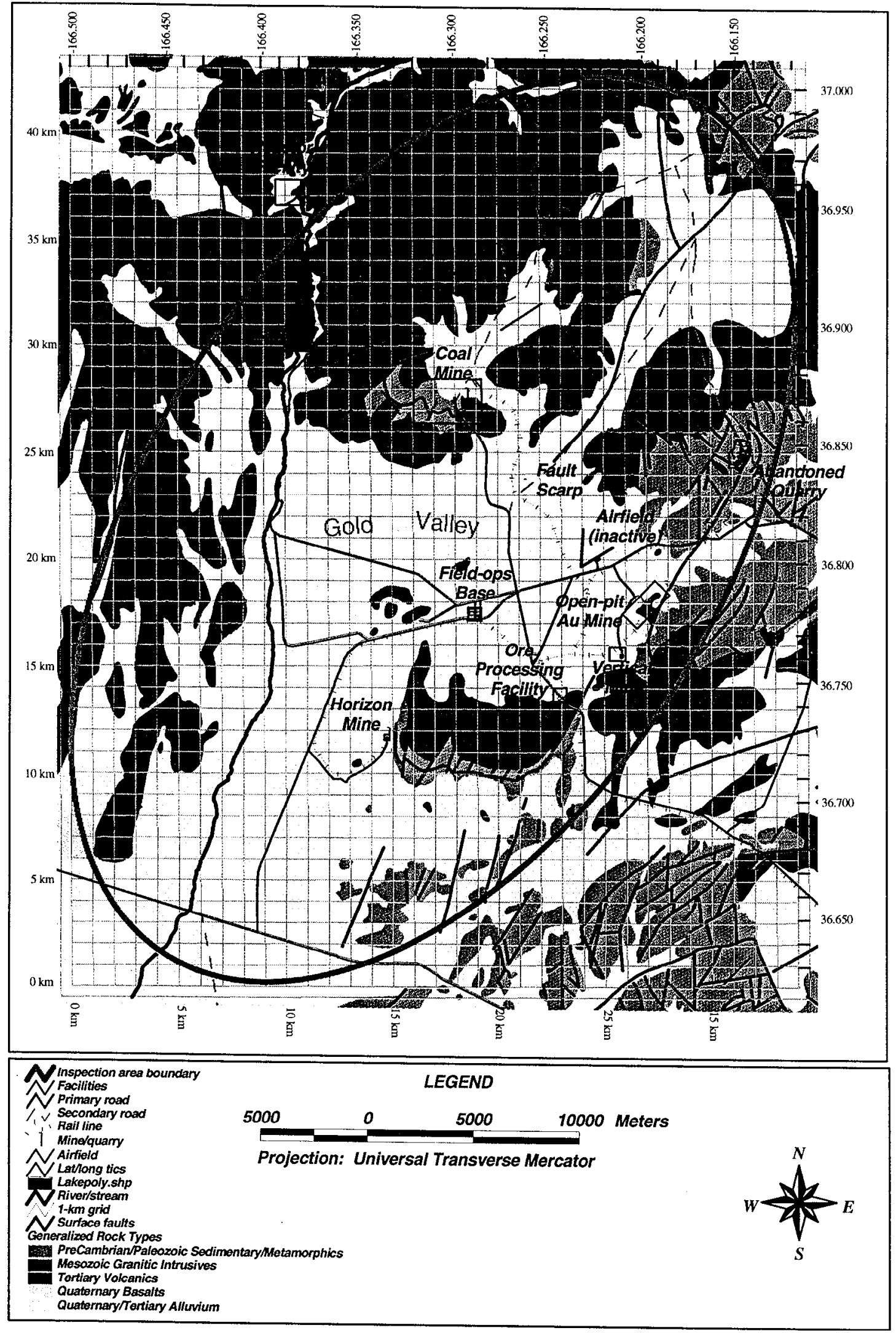

Generalized Geologic Map of the Gold Valley Area. 
Appendix II

U.S. Scenario Consultation and Clarification Package 


\section{CTRTO RESTRICTED}

CTBTO

The Comprehensive Test-Ban Treaty Organization

P.O. Box 400, Wagramerstrasse 5, A-1200, Vienna, Austria

Tel (+43-1) .... Fax $(+43-1)$....E-mail .....@CTBTO.org

Form Number: F06

From: Comprehensive Test-Ban Treaty Organization

To: State of $Y$

Precedence: Immediate

Subject: Request for Clarification

Index: CTBTO/EC/ODG/0001/1998/10/07/1700GMT/F06

References: None

Content:

At 14:00 GMT on 7 October 1998, the CTBTO received the following Request for Assistance in clarifying a matter of CTBT concern from the State of $X$ :

A. Pursuant to Article IV.C. paragraph 32 the State of $X$ requests the Executive Council to assistance in clarifying a matter which causes us concern about possible non-compliance with the basic obligations of the Treaty by the State of $Y$.

B. On 3 October 1998 at 22:32:12 GMT, the International Monitoring System detected IDC Event 0654321 , a $4.0\left(\mathrm{~m}_{\mathrm{b}}\right)$ magnitude seismic event in the vicinity of $35.2861 \mathrm{~N} 165.1396 \mathrm{E}$ at a depth of less than ten kilometers.

C. In accordance with IDC event screening criteria based on a ratio of magnitude of surface waves to body waves this event with a high probability is of explosive nature. Before now such a level of explosive activity has never been detected by IMS in this area.

D. Request immediate consultation and clarification with the State of $Y$ to resolve the concern about possible non-compliance.

The Executive Council forwards aforecited Request to the State of $Y$ to obtain clarification pursuant to Article IV.C. paragraph 32 b).

Remarks: None

End of CTBTO/EC/ODG/0001/1998/10/07/1700GMT/F06

CTBTO RESTRICTED 


\section{CTBTO RESTRICTED}

\section{CTBTO}

The Comprehensive Test-Ban Treaty Organization

P.O. Box 400, Wagramerstrasse 5, A-1200, Vienna, Austria Tel (+43-1) .... Fax (+43-1) ....E-mail .....@CTBTO.org

Form Number: F07

From: Comprehensive Test-Ban Treaty Organization

To: State of $X$

Precedence: Immediate

Subject: Response to Request for Clarification

Index: CTBTO/EC/ODG/0002/1998/10/09/1300GMT/FO7

References:

A. CTBTO/EC/ODG/0001/1998/10/07/1700GMT/F06

\section{Content:}

At 12:43 GMT on 9 October 1998, the CTBTO received the following Response to Request for Clarification from the State of $Y$ :

A. In response to the compliance concern stated in Reference A., the Government of the State of $Y$ confirms a fait accompli of carrying out an explosion in the area mentioned in that request. This sub-surface chemical explosion of conventional explosive with total yield of 500 TNT took place on 3 October 1998 at approximately 22:32 GMT in the vicinity of $35.2200 \mathrm{~N}$ $165.1892 \mathrm{E}$, in an open-cast mine. This explosion was carried out within a framework of development of a new cost-effective method of crashing mining rocks.

B. A number of conventional explosions of about 100 TNT yield were carried out in this quarry earlier during the last year on a regular basis. These explosions were detected by IMS as 2.5 to 3.0 magnitude seismic events and didn't cause any compliance concern.

c. None of IMS Radionuclide Stations detected any evidences of noncompliance. That network includes two Radionuclide Stations within 1500 kilometers of the place of above mentioned explosion detected as IDC event 0654321 , and one of these two stations is capable to detect radioactive noble gases.

The Executive Council forwards aforecited Clarification to the State of $X$ pursuant to Article IV.C. paragraph $32 \mathrm{c}$ ).

Remarks: None End of CTBTO/EC/ODG/0002/1998/10/09/1300GMT/F07 


\section{CTBTO RESTRICTED}




\section{CTBTO RESTRICTED}

\section{CTBTO}

The Comprehensive Test-Ban Treaty Organization

P.O. Box 400, Wagramerstrasse 5, A-1200, Vienna, Austria

Tel (+43-1) .... Fax (+43-1) ....E-mail .....@CTBTO.org

Form Number: F08

From: Comprehensive Test-Ban Treaty Organization

To: State of $Y$

Precedence: Immediate

Subject: Request for Clarification

Index CTBTO/DG/ODG/0001/1998/10/13/1400GMT/F08

References: .

$\begin{array}{ll}\text { A. } & \text { CTBTO/EC/ODG/0001/1998/10/07/1700GMT/F06 } \\ \text { B. CTBTO/EC/ODG/0002/1998/10/09/1300GMT/F07 }\end{array}$

Content:

At 11:07 GMT on 13 October 1998, the CTBTO Council received the following On-Site Inspection Request from the State of $X$ :

A. The State of $X$ has thoroughly analyzed the data provided in Clarification Response of the State of $Y$

(CTBTO/EC/ODG/0002/1998/10/09/1300GMT/F07) and deems them unsatisfactory. The State of $X$ requests for instant on-site inspection in the area of the State of $Y$ shown in Attachment 1. Additional data are provided below.

B. Boundaries of the proposed inspection area of $1000 \mathrm{KM}^{2}$ are shown on the map of Attachment 1. The area includes 35.2861N 165.1306E, the location of IDC Event 0654321 . The error in positioning on IDC data is 11.8 $\mathrm{km}$, the most plausible depth range is of 0 to $10 \mathrm{~km}$. On IDC data the event took place at 22:32:12 GMT on 3 October 1998. Probable environment of the event is rocks deposited within the above depth range.

C. The area also includes $35.2200 \mathrm{~N} 165.1892 \mathrm{E}$ declared by the State of $Y$ as the place of chemical explosion detected as IDC Event 0654321 . The assertion that it was the chemical explosion with the parameters specified in the Clarification of the State of $Y$ that caused the seismic signal corresponding to the event 0654321 , is not in compliance with the IDC stated magnitude of body wave of 4.0 under any of the received models of its propagation in the area.

D. IMS Infrasonic Station within the distance of about $340 \mathrm{~km}$ of the vicinity of Event 0654321 detected a signal which could be caused by the 
chemical explosion said in the Clarification of State of Y. However, the level of the infrasonic signal is close to those ones detected there earlier during the last year of sub-surface chemical explosions which were of about 100 TNT yield, as State of $Y$ confirmed. Thus, the data of infrasonic monitoring do not agree with the information of the State of $Y$ about the yield of the chemical explosion and cause further doubts that the detected seismic signal was generated by this chemical explosion.

E. Materials of the consultations and clarifications are fully provided in CTBTO/EC/ODG/0001/1998/10/07/1700GMT/F06 and

CTBTO/EC/ODG/0002/1998/10/09/1300GMT/F07. The State of $X$ considers it necessary to note that prior to Request for Clarification presented in CTBTO/EC/ODG/0001/1998/10/07/1700GMT/F06, the State of $Y$ has not provided Technical Secretariat with any information on the national use of chemical explosion of the yield higher than 300 TNT as stated in Part III paragraph 2 of Protocol to the Treaty.

F. On available data; the State of $Y$ has lately intensified the effort in its nuclear program causing the concern about its potential weapon purpose. We know about the attempt undertaken at the end of 1977 to make the contact with "DUST" company on procurement of the dual-use equipment that could be used for producing weapon-grade fissile materials. The attempt was undertaken in diversion of effective international limitations and only the intervention of IAEA prevented from violation of the rules.

$G$. The State of $X$ believes the above data related to the detection of the seismic event 0654321 are sufficiently ambiguous to warrant this On-Site. Inspection Request to clarify whether a nuclear weapon test or other nuclear explosion has been carried out in violation of Article 1 of the Treaty.

Director General forwards aforecited Request to the State of $Y$ pursuant to Article IV.C. paragraph 49.

Remarks: None

End of CTBTO/DG/ODG/0001/1998/10/13/1400GMT/F08

\section{CTBTO RESTRICTED}

\section{Attachment 1 \\ Map of the inspection area \\ $<<$ see file MAP.GIF>>}

Note: the inspection area is located in weekly mountainous terrain, elevation changes up to 250 meters. There are no inaccessible places except for small swamps. Nearly whole area is covered with mixed forests. Map legend: blue rivers and lakes, yellow - asphalt roads, grey and dashed black - dirt roads, bold black line - railroad, red - boroughs and buildings, purple - aerial power lines. The inspection area is a square with $31.5 \mathrm{~km}$ side. 


\section{CTBTO RESTRICTED}

\section{CTBTO}

The Comprehensive Test-Ban Treaty Organization

P.O. Box 400, Wagramerstrasse 5, A-1200, Vienna, Austria

Tel (+43-1) .... Fax (+43-1) ....E-mail ....@CTBTO.org

Form Number: F09

From: Comprehensive Test-Ban Treaty Organization

To: State of $Y$

Precedence: Immediate

Subject: Director-General Request for Clarification

Index: CTBTO/DG/ODG/0002/1998/10/13/1401GMT/F09

References:

A. CTBTO/EC/ODG/0001/1998/10/07/1700GMT/F06

B. CTBTO/EC/ODG/0002/1998/10/09/1300GMT/F07

C. CTBTO/DG/ODG/0001/1998/10/13/1400GMT/F08

\section{Content:}

Pursuant to Article IV.C. paragraph 42 of the Treaty Director-General requests the State of $Y$ to provide clarifications specified below in order to clarify and resolve the On-Site Inspection Request received from the State of $X($ Ref. $\tilde{N})$.

A. Provide explanations to resolve the conflict between magnitude of the seismic event detected as IDC Event 0654321 and declared yield of the chemical explosion which is the said event, as asserts the State of $X$.

B. Provide explanations to clarify the data of infrasonic monitoring mentioned in Ref. $\mathrm{C}$ in relation to the yield of the chemical explosions which were carried out, as the State of $Y$ declared (Ref. B), in the vicinity of the event 0654321.

C. Provide explanations and other relevant information the State of $Y$ would consider appropriate for clarifying other concerns of Ref. $C$ including the items $F$ and $G$ of the reference.

Remarks: None

End of CTBTO/DG/ODG/0002/1998/10/13/1401GMT/F09

CTBTO RESTRICTED 


\section{CTETO RESTRICTED}

\section{CTBTO}

The Comprehensive Test-Ban Treaty Organization

P.O. Box 400, Wagramerstrasse 5, A-1200, Vienna, Austria

Tel (+43-1) .... Fax $(+43-1)$....E-mail ....@CTBTO.org

Form Number: F10

From: Comprehensive Test-Ban Treaty Organization

To: All States Parties

Precedence: Immediate

Subject: Response to Director-General Request for Clarification

Index: CTBTO/DG/ODG/0003/1998/10/15/1733GMT/F10

\section{References: .}
A. CTBTO/EC/ODG/0001/1998/10/07/1700GMT/F06
B. CTBTO/EC/ODG/0002/1998/10/09/1300GMT/F07
C. CTBTO/DG/ODG/0001/1998/10/13/1400GMT/F08
D. CTBTO/DG/ODG/0002/1998/10/13/1401GMT/F09

\section{Content:}

At 16:27 GMT on 15 October 1998 the CTBTO received the following Response to Director-General Request for Clarification from the State of $Y$ (Ref. D):

A. The State of $Y$ already provided the Executive Council with the information on nature of the event detected by IDC as Event 0654321 in Reference CTBTO/EC/ODG/0002/1998/10/09/1300GMT/F07. The State of $Y$ confirms that the sub-surface chemical explosion of conventional explosive with total yield of 500 tons TNT took place on 3 October 1998 at approximately $22: 32$ GMT in the vicinity of $35.2200 \mathrm{~N} 165.1892 \mathrm{E}$, in an opencast mine.

B. We recognise the anomalous high seismic effect of the case in question. A nature of this anomaly is not completely clear and is at present under consideration of our experts. After completing the consideration relevant materials will be provided to the CTBTO. In this connection we would like to note that some other facts are known concerning the detection of the anomalous high seismic effect of chemical explosions, for instance, the results obtained in the course of joint US-Kazakhstan experiments carried out in July-September 1997 at the former Semipalatinsk Test Site.

C. Weather conditions along the signal path may have affected the results of infrasonic monitoring. Unfortunately, there are no direct confident data on speed of wind and other conditions in the area that could be used for 
numerical estimates. In addition; the signal of the explosion in question, like the signals of earlier explosions, is rather weak and the measurement error is of great importance. Therefore, we believe that there is not any conflict between the parameters we provided of the chemical explosion and the data of infrasonic monitoring.

D. As it is known, within the framework of confidence-building measures providing Technical Secretariat with any information on the national use of the chemical explosions yielding higher than 300 tons TNT provided by Part III paragraph 2 of Protocol to the Treaty is a voluntary measure. We consider groundless all the doubts about the above explosion, however, as the evidence of our readiness to cooperation with the Organisation, we clarify that the explosion has not been notified in advance to avoid any preventing actions of the so-called environment protection movement hampering this extremely important for economy of the region mining activity.

E. We believe the Request does not concern in any way the problem related to the contract on procurement of equipment for producing fissile materials needed for our nuclear energy program which is being implemented in full compliance with our international obligations. We remind that in the arguable juridical situation our state voluntarily refused the contract and the problem was closed that was confirmed in an official IAEA declaration.

Remarks: None

End of CTBTO/DG/ODG/0003/1998/10/15/1733GMT/F10

CTBTO RESTRICTED 


\section{CTBTO RESTRICTED}

\section{CTBTO}

The Comprehensive Test-Ban Treaty Organization

P.O. Box 400, Wagramerstrasse 5, A-1200, Vienna, Austria

Tel (+43-1) .... Fax (+43-1) ....E-mail ....@@TBTO.org

Form Number: F11

From: Comprehensive Test-Ban Treaty Organization

To: State of $Y$

Precedence: Immediate

Subject: Notification of Inspection

Index: CTBTO/DG/ODG/0004/1998/10/15/2332GMT/F11

References:
A. CTBTO/EC/ODG/0001/1998/10/07/1700GMT/F06
B. CTBTO/EC/ODG/0002/1998/10/09/1300GMT/F07
C. CTBTO/DG/ODG/0001/1998/10/13/1400GMT/F08
D. CTBTO/DG/ODG/0002/1998/10/13/1401GMT/F09
E. CTBTO/DG/ODG/0003/1998/10/15/1733GMT/F10

\section{Content:}

Pursuant to Article IV.C. paragraph 55 Director-General forwards the following On-Site Inspection Notification to the State of $Y$ :

\section{A. INSPECTION MANDATE:}

a) Executive Council Decision: The Executive Council has resolved (with a vote of 47 members present $=31$ affermative/ 11 negative/ 5 abstentions) that the request by the State of $X$ (Ref. $C$ ) is sufficiently justified and hereby approves the on-site inspection request to clarify whether a nuclear weapon test explosion or any other nuclear explosion has been carried out in violation of Article I of the Treaty and collect all the data which could help identify any potential violator.

b) State Party to be Inspected: State of $Y$

c) Location of Inspection Area: 1,000 KMㄹ ${ }^{2}$ area including $35.2861 \mathrm{~N}$ 165.1306E with boundaries in accordance with those drawn on the attached map (Attachment I).

d) Planned Types of Activity of the Inspection Team in the Inspection Area: At the initial step provided by Article IV.C. paragraph 47 all the activities specified in Part II.D. paragraph 69 (a) through (e) are planned except gamma-survey of the surface of the inspected area with radiation spectra 


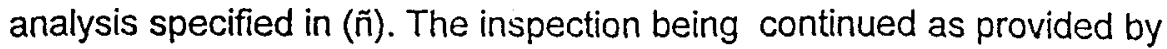
Article IV.C. paragraph 47 , as well as drilling being decided as provided by Article IV.C. paragraph 48 , this item of the mandate is subject to relevant additions. of $Y$.

e) Point of Entry to be used by Inspection Team: Airport "Alpha", State

f) Transit and/or Basing Points: N/A

g) Head of the Inspection Team:

Ifft, Edward Milton

h) Members of the Inspection Team:

1. Filarowski, Christina A.

2. Gough, Robert

3. Hawkins, Ward Leslie

4. Knowles, Cyrus Phillipp

5. Kreek, Steven Andrew

6. MacLeod, Gordon Avery

7. Rockett, Paul David

8. Russell, James William

9. Schroeder, Judith Kay

10. Smith, Albert Turner, Jr.

11. Sweeney; Jerry Joseph

12. Wild, John Frederick

13. Wohletz, Kenneth Harold

14. Zucca, John Justin

15. Dunlop. William Henry

16. Antonucci, Daria Susan

17. Wolcott, John Heren

18. Scheinman, Adam Mark

19. Chi, Hans-Wolfgang

20. Evans, David Earl

21. Hardiman, Tara $L$.

22. Donnelly, Dorothy Carlson

23. Turnbull, Lawrence

24. Ray, Terrill Wylie

i) Proposed Observer: no

i) List of the Equipment to be Used in the Inspection Area:

List of equipment for the initial step of the inspection is provided in Attachment 2 . The inspection being continued as provided by Article IV.C. paragraph 47 , as well as drilling being decided as provided by Article IV.C. paragraph 48 , this item of the mandate is subject to relevant additions.

B. Date and estimated time of arrival at point of entry: 19 October 1998, 09.00 Local.

C. Means of arrival at point of entry: Flight $A B C 1234$

D. Permanent number of diplomatic permission for non-scheduled flight: N/A.

E. Director-General requests the state of $Y$ to make available the 
equipment listed in Attachment 3 for the inspection team.

F. Director-General requests the state of $Y$ to provide the inspection team with the following services, as stated in Part II paragraph 11 of Protocol to the Treaty:

1. Hotel-like accommodations for all members of the team with standard services

2. Heated offices with furniture (tables and chairs) of totally 100 square metres with electrical power $(220 \mathrm{~V}$, total power to $10 \mathrm{~kW})$

3. Heated workplace of 100 square metres with electrical power (220V, total power to $50 \mathrm{~kW}$ ) for equipment test and maintenance.

4. Stationary three meals and drinking water to standards

5. Standard foodstuffs and water in portable containers for field feed

6. Access to medical services, if necessary

7. Suitable transportation for inspection personnel and equipment and required fuels and lubricants

8. Interpretation services (2 interpreters educated in English and technical terms)

Remarks: Estimate 40 cubic metres (3300 kilograms) of approved inspection equipment and personal baggage arriving with inspection team at the point of entry.

End of CTBTO/DG/ODG/0004/1998/10/15/2332GMT/F11

\section{CTBTO RESTRICTED}

Attachment 1

The Map of the Inspection Area to Mandate provided in CTBTO/DG/ODG/0004/1998/10/15/2332GMT/F11

See file $<$ Map.Tif $>$

Attachment 2

List of Approved Inspection Equipment to Mandate provided in CTBTO/DG/ODG/0004/1998/10/15/2332GMT/F11

$1 \ldots$

Attachment 3

List of Equipment Requested from the Inspected State Party to Notification provided in CTBTO/DG/ODG/0004/1998/10/15/2332GMT/F11

$1 .$. 
Appendix III

Exercise Planning, Coordination, Development and Implementation Team 


\section{Exercise Planning, Coordination, Development and Implementation Team}

US TEAM

\section{SPONSOR}

Adam Scheinman, Office of Arms

Control and Nonproliferation, DOE

CONTROL TEAM HEAD

Christina Filarowski, LLNL

CONTROL TEAM MEMBERS

Robert Gough, SNL

Ward Hawkins, LANL

Cyrus Knowles, DTRA

Steven Kreek, LLNL

Gordon Macleod. NVOO

Paul Rockett, SNL

James Russell, NVOO

Judy Schroeder, OSD

Albert Smith, LLNL

Jerry Sweeney, LLNL

John Wild, LLNL

Kenneth Wohletz, LANL

\section{OTHER US PARTICIPANTS}

Daria Antonucci, DOE/DynMeridian Hans Chi, ACDA

William Dunlop, LLNL

Tara Hardiman, State Department

Edward Ifft, DTRA

Lawrence Turnbull, State Department

\section{INTERPRETERS}

Pavel Oleynikov

Lada Talentova

Irina Zyryanova

Irina Malofeeva

Sergey Shatalov

Grigory Shkalikov

RF TEAM

CONTROL TEAM HEAD

Vladimir Legon'kov

OTHER RF PARTICIPANTS

Vladimir Nogin

Vadim Smirnov

Yuri Sakharov

Valery Blyum

Vitaly Shchukin

Andrey Dubina

Mikhail Sakharov

Sergey Demjyanovski

Aleksander Petrovtsev

Valery Antoshev

Nikolay Ivashkin

Yuri Kaplan

Dmitry Sagaradze

Alexander Usachjov

Vladimir Tal'drik

Alexander Perevozin

Viktor Zaikin

Alexei Pchelin

Nikolay Kozeruk

Yuri Gvozdarev

Fedor Kripichev

Andrey Noskov

Ivan Nevraev

Vladimir 'lyustin

Dmitry Moshkin

Vasiliy Tereshchenko

Evgeny Gorbachev

Yuri Sotnikov

Valery Savin

Anatoly Savinykh

Boris Lukishov

Arshak Ter-Semenov

Yuri Khokhlov

Aleksander Nizamov

Yuri Popov

Vladimir Mokrousov

Igor Tyurin

Vladimir Drujinin 